
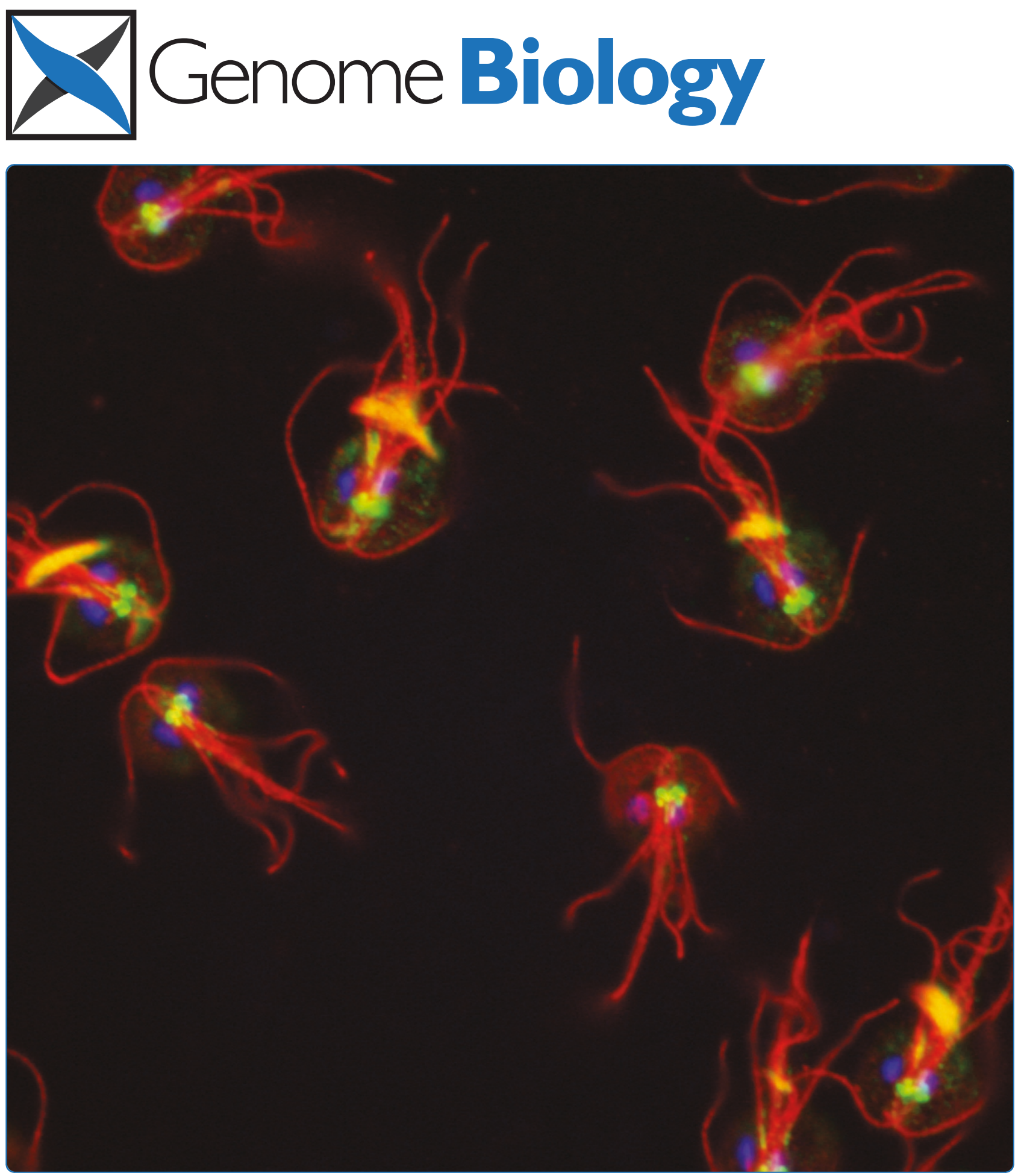

The minimal kinome of Giardia lamblia illuminates early kinase evolution and unique parasite biology

Manning et al. 


\title{
The minimal kinome of Giardia lamblia illuminates early kinase evolution and unique parasite biology
}

\author{
Gerard Manning ${ }^{1 *}$, David S Reiner ${ }^{2,3,4}$, Tineke Lauwaet ${ }^{2}$, Michael Dacre ${ }^{1}$, Alias Smith ${ }^{2}$, Yufeng Zhai ${ }^{1}$, Staffan Svard ${ }^{5}$
} and Frances D Gillin ${ }^{2}$

\begin{abstract}
Background: The major human intestinal pathogen Giardia lamblia is a very early branching eukaryote with a minimal genome of broad evolutionary and biological interest.

Results: To explore early kinase evolution and regulation of Giardia biology, we cataloged the kinomes of three sequenced strains. Comparison with published kinomes and those of the excavates Trichomonas vaginalis and Leishmania major shows that Giardia's 80 core kinases constitute the smallest known core kinome of any eukaryote that can be grown in pure culture, reflecting both its early origin and secondary gene loss. Kinase losses in DNA repair, mitochondrial function, transcription, splicing, and stress response reflect this reduced genome, while the presence of other kinases helps define the kinome of the last common eukaryotic ancestor. Immunofluorescence analysis shows abundant phospho-staining in trophozoites, with phosphotyrosine abundant in the nuclei and phosphothreonine and phosphoserine in distinct cytoskeletal organelles. The Nek kinase family has been massively expanded, accounting for 198 of the 278 protein kinases in Giardia. Most Neks are catalytically inactive, have very divergent sequences and undergo extensive duplication and loss between strains. Many Neks are highly induced during development. We localized four catalytically active Neks to distinct parts of the cytoskeleton and one inactive Nek to the cytoplasm.
\end{abstract}

Conclusions: The reduced kinome of Giardia sheds new light on early kinase evolution, and its highly divergent sequences add to the definition of individual kinase families as well as offering specific drug targets. Giardia's massive Nek expansion may reflect its distinctive lifestyle, biphasic life cycle and complex cytoskeleton.

\section{Background}

Protein kinases modulate most cellular pathways, particularly in the co-ordination of complex cellular processes and in response to environmental signals. About $2 \%$ of genes in most eukaryotes encode kinases, and these kinases phosphorylate over $30 \%$ of the proteome [1]. Kinases regulate the activity, localization and turnover of their substrates. Most kinases have dozens of substrates, and operate in complex, multi-kinase cascades. Hence, organisms with reduced kinomes can provide simple model systems to dissect kinase signaling.

\footnotetext{
* Correspondence: manning@salk.edu

${ }^{1}$ Razavi Newman Center for Bioinformatics, The Salk Institute for Biological

Studies, 10010 North Torrey Pines Road, La Jolla, CA 92037, USA

Full list of author information is available at the end of the article
}

The unicellular human gut parasite Giardia lamblia cycles between a dormant cyst stage and a virulent trophozoite, both of which are adapted to survival in different inhospitable environments [2]. The life cycle starts with the ingestion of the cyst by a vertebrate host. Exposure to gastric acid during passage through the host stomach triggers excystation and the parasite emerges in the small intestine after stimulation by intestinal factors $[3,4]$. The excyzoite [5] quickly divides into two equivalent binucleate trophozoites that attach to and colonize the small intestine. Trophozoites carried downstream by the flow of intestinal fluid differentiate into dormant quadrinucleate cysts. Cysts are passed in the feces, and can survive for months in cold water until they are ingested by a new host. Trophozoites are half-pear shaped and are characterized by four pairs of flagella, a

\section{() Biomed Central}


ventral attachment disk and a median body (Figure 1). Each pair of flagella has a distinct beating pattern and likely has dedicated functions in swimming and attachment $[6,7]$.

The recent genome sequencing of strains from three assemblages (broadly equivalent to subspecies) of Giardia lamblia (syn. intestinalis) [8-10] revealed a compact genome of approximately 6,500 ORFs that is highly divergent in sequence from other eukaryotes. Many conserved pathways have substantially fewer components than in similarly sized genomes [8]. Its minimal genome and the ability to culture and induce its complex life and cell cycle in vitro make Giardia an appealing model for studying the signaling underlying entry into and emergence from dormancy in a pathogen.

Few kinases and phosphorylation patterns have been studied in Giardia (Table 1) [11,12]. Functional studies [13-16] suggest that regulation of protein phosphorylation by kinases and phosphatases plays a central role in modulating the dramatic remodeling of the parasite's morphology as it cycles between the dormant infectious cyst and the motile, virulent trophozoite (Table 1). Many of the known signaling proteins localize to cytoskeletal structures unique to Giardia, which may confer functional specificity (Figure 1).

Protein kinases are well-studied in other organisms, control most aspects of cellular functions, and are proven therapeutic targets. Hence, analysis of the Giardia kinome may give valuable insight into this parasite's biology and the evolution of signaling.

\section{Results and discussion}

We cataloged the Giardia kinome using hidden Markov model (HMM) profiles and Blast searches of genomic and EST sequences from three sequenced strains: two established human pathogens, WB (assemblage A) [8] and GS (assemblage B) [9], that appear to span the divergence of isolates infectious to humans, and a recently isolated porcine strain, P15 (assemblage E) [10]. Despite their shared genus name, these genomes are quite divergent, with an average of $90 \%$ protein sequence identity between WB and P15, and approximately 79\% between these two strains and GS [10].

We found 278 protein kinases in the WB strain (Table 2; Additional file 1), 272 in GS, and 286 in P15, using release 2.3 of the Giardia genomes [17]. These include 46 new gene predictions and 86 sequences not previously annotated as kinases. We also extend 30 fragmentary gene predictions from WB to longer pseudogene sequences. Remarkably, over $70 \%$ of the kinome belongs to a huge expansion of one family, the Nek kinases. Since these have so many unusual characteristics, we will refer to the 80 non-Nek kinases as the core kinome and consider the Nek expansion separately.

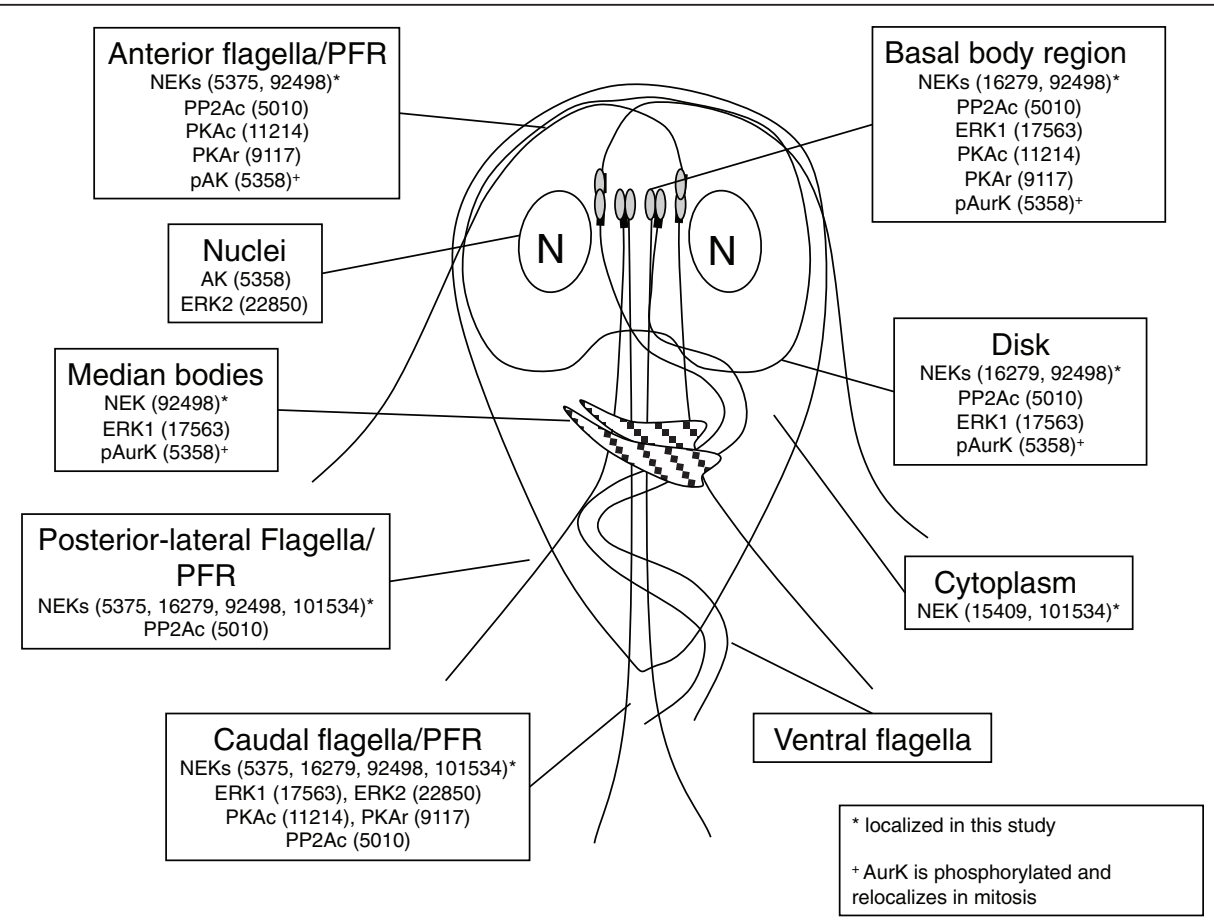

Figure 1 Cartoon of an interphase Giardia trophozoite showing kinases that have been immunolocalized to date. The localizations of previously described kinases, PP2A and the Nek kinases reported in this study are shown. In most cases, the kinases localize to the intracellular flagella-associated paraflagellar dense rods (PFRs), rather than to the axonemes. (Modified from [64].) 
Table 1 Giardia protein and lipid kinases and protein phosphatases published to date

\begin{tabular}{|c|c|c|c|c|c|}
\hline Kinase & $\begin{array}{l}\text { ORF } \\
\text { ID }\end{array}$ & Localization (immunofluorescence, tag or specific antibody) & $\begin{array}{l}\text { Protein } \\
\text { expression } \\
\text { (immunoblot) }\end{array}$ & Reported function & Reference \\
\hline $\begin{array}{l}\text { Aurora } \\
\text { kinase } \\
\text { (Aurk) }\end{array}$ & 5358 & $\begin{array}{l}\text { Interphase: nuclei. Mitosis: activated by phosphorylation. pAurK: } \\
\text { centrosomes, spindle, anterior PFR, median body, parent attachment } \\
\text { disk }\end{array}$ & $\begin{array}{l}\text { Constant in } \\
\text { encystation }\end{array}$ & $\begin{array}{l}\text { Mitosis, cell cycle } \\
\text { (inhibitors) }\end{array}$ & [52] \\
\hline PKAC & 11214 & Basal bodies, anterior, caudal PFR. Encystation: basal bodies only & $\begin{array}{l}\text { Constant in } \\
\text { encystation }\end{array}$ & $\begin{array}{l}\text { Encystation, } \\
\text { excystation (inhibitors) }\end{array}$ & {$[13,14]$} \\
\hline PKAr & 9117 & Basal bodies, anterior, caudal PFR. Encystation: greatly decreased & $\begin{array}{l}\text { Strongly decreased } \\
\text { in encystation }\end{array}$ & $\begin{array}{l}\text { Decreases activity of } \\
\text { PKAc }\end{array}$ & [14] \\
\hline Akt (PKB) & 11364 & & & & {$[47]$} \\
\hline ERK1 & 17563 & Median body, outer edge of attachment disk & $\begin{array}{l}\text { Gradually reduced } \\
\text { during encystation }\end{array}$ & $\begin{array}{l}\text { Reduced activity in } \\
\text { encystation }\end{array}$ & [16] \\
\hline ERK2 & 22850 & Nuclei, caudal flagella. Encystation: cytoplasmic, punctate & $\begin{array}{l}\text { Not greatly } \\
\text { changed in } \\
\text { encystation }\end{array}$ & $\begin{array}{l}\text { Reduced activity in } \\
\text { encystation }\end{array}$ & [16] \\
\hline PI3K1 & 14855 & & & Growth (inhibitors) & {$[48,49]$} \\
\hline $\mathrm{Pl} 3 \mathrm{~K} 2$ & 17406 & & & Growth (inhibitors) & {$[48,49]$} \\
\hline PI4K & 16558 & & & Growth (inhibitors) & {$[48]$} \\
\hline PKA & 86444 & [Reported as a PKC $\beta]$ & & & [24] \\
\hline TOR & 35180 & & & & {$[48,50]$} \\
\hline \multicolumn{6}{|l|}{$\begin{array}{l}\text { Protein } \\
\text { phosphatase }\end{array}$} \\
\hline PP2AC & 5010 & $\begin{array}{l}\text { Basal bodies, anterior, caudal, posterior-lateral PFR. Encystation: } \\
\text { localization to anterior PFR lost, cyst wall }\end{array}$ & $\begin{array}{l}\text { Highest in cysts, } \\
\text { stage I excystation }\end{array}$ & $\begin{array}{l}\text { Encystation, } \\
\text { excystation (inhibitor, } \\
\text { antisense) }\end{array}$ & {$[15]$} \\
\hline
\end{tabular}

PFR, paraflagellar rod. See Additional file 4 for definitions.

\section{The core kinome}

The core kinome of 80 kinases is completely conserved between the three genomes. Sixty-one core kinases can be classified into 49 distinct classes (families or subfamilies) that are conserved in many other eukaryotes [18-23]; the remaining 19 include 5 in two small Giardia-specific families, and 14 with no close homologs (Table 2; Additional file 1). Giardia sequences are typically the most divergent of any within their families: comparison of a set of nine universally conserved kinase domain orthologs from human to various deep-branching lineages showed an average sequence identity of only $40 \%$ for Giardia, compared with $46 \%$ for the related excavate Trichomonas vaginalis, and 46 to $50 \%$ for other deep-branching lineages (ciliates, plants, fungi) (Additional file 2). This indicates that Giardia sequences are remarkably divergent, even for an early-branching lineage, and provides a useful resource to study the limits of how sequences can vary while still retaining their family-specific functions. Thus, Giardia encodes the smallest and most sequence-divergent of studied eukaryotic kinomes, other than those of parasites that have not been cultured axenically. No core kinome class has more than three members in Giardia, suggesting a lack of recent duplication and expansion into specialized functions.
Two previously predicted kinases could not be found: a protein kinase $C$ (PKC) was inferred earlier by reactivity to antibodies against mammalian PKCs and by PKCselective inhibitors [24], but no clear PKC homolog is seen in the genome sequence. Similarly, although an insulin-like growth factor receptor (IGFR) kinase was inferred by antibody binding and association with phosphotyrosine [25], we could not find an IGFR in the genomes of Giardia or any other protist.

\section{Evolutionary origin and functional repertoire of the Giardia kinome}

To probe the origin of the Giardia kinome, we annotated the kinomes of two other excavates, Trichomonas vaginalis [26] and Leishmania major [27] (Additional file 3 ). The excavates are one of about six anciently diverged 'supergroups' of eukaryotes, whose relationship to each other is uncertain [28]. Excavates include free-living, symbiotic, and parasitic protists, many flagellated and often with reduced mitochondria. Comparison of the three excavate kinomes predicts a rich kinome of 68 distinct kinases in their common ancestor, with substantial losses of core kinases in extant species, possibly due to their reduced parasitic lifestyles [29] (Figure 2, Table 2). These losses provide a valuable model to explore the effect of gene deletion 
Table 2 Summary of Giardia kinome classification

\begin{tabular}{|c|c|c|c|c|c|}
\hline Group & Family & Subfamily & Count & ORF ID & Notes \\
\hline \multicolumn{6}{|c|}{ Primordial kinases in Giardia strain WB (core kinome plus Nek1) } \\
\hline AGC & Akt & & 1 & 11364 & Metabolic rate control \\
\hline AGC & NDR & $\begin{array}{l}\text { NDR- } \\
\text { unclassified }\end{array}$ & 2 & 8587, novel & Mitotic exit, morphology, centrosomes \\
\hline AGC & PDK1 & & 1 & 113522 & Lipid signaling, AGC master kinase \\
\hline AGC & PKA & & 2 & 11214,86444 & CAMP responsive kinase \\
\hline AGC & PTF & FPK & 1 & 221692 & Potential flippase kinase \\
\hline CAMK & CAMK1 & & 1 & 11178 & Calcium-dependent signaling \\
\hline CAMK & CAMKL & AMPK & 3 & $\begin{array}{l}14364,16034 \\
17566\end{array}$ & Energy metabolism \\
\hline CK1 & CK1 & CK1-D & 1 & 7537 & Absent from ciliates and plants \\
\hline CMGC & CDK & $\mathrm{CDC2}$ & 3 & $15397,8037,9422$ & Master kinase of cell cycle \\
\hline CMGC & CDK & CDK5 & 1 & 16802 & Non-cell cycle CDK \\
\hline CMGC & $\mathrm{CDKL}$ & & 1 & 96616 & Functions unknown \\
\hline CMGC & CK2 & & 1 & 27520 & Diverse functions, hundreds of substrates \\
\hline CMGC & CLK & & 1 & 92741 & Splicing and other functions \\
\hline CMGC & DYRK & DYRK1 & 1 & 101850 & Not in ciliates, Trichomonas, or moss \\
\hline CMGC & DYRK & DYRK2 & 3 & $\begin{array}{l}137695,17417 \\
17558\end{array}$ & Varied functions \\
\hline CMGC & GSK & & 2 & 17625,9116 & Glycogen synthase kinase 3. Diverse functions \\
\hline CMGC & MAPK & ERK1 & 1 & 17563 & Canonical MAPK pathway \\
\hline CMGC & MAPK & ERK7 & 1 & 22850 & Variant MAPK gene \\
\hline CMGC & RCK & MAK & 2 & 14172,6700 & Meiosis, flagella \\
\hline CMGC & RCK & MOK & 1 & 14004 & Flagellar regulation \\
\hline CMGC & SRPK & & 1 & 17335 & Splicing \\
\hline Other & Aur & & 1 & 5358 & Mitotic kinase \\
\hline Other & Bud32 & & 1 & 16796 & Telomere associated (KEOPS complex) \\
\hline Other & CAMKK & & 1 & 96363 & CAMK kinase \\
\hline Other & $\mathrm{CDC7}$ & & 1 & 112076 & Cell cycle \\
\hline Other & IKS & & 1 & 137730 & Not in ciliates or moss \\
\hline Other & NAK & $\begin{array}{l}\text { NAK- } \\
\text { unclassified }\end{array}$ & 2 & 12223,2583 & Varied functions \\
\hline Other & NEK & NEK1 & 1 & 137719 & $\begin{array}{l}\text { Flagellar and centrosomal functions. Only Nek with clear non-excavate } \\
\text { orthologs }\end{array}$ \\
\hline Other & PEK & GCN2 & 1 & 12089 & Response to amino acid starvation \\
\hline Other & PLK & PLK1 & 1 & 104150 & Mitotic kinase. Lost in plants \\
\hline Other & SCY1 & & 1 & 8805 & Cryptic functions \\
\hline Other & TTK & & 1 & 4405 & Not in ciliates or moss \\
\hline Other & ULK & Fused & 1 & 17368 & Varied functions \\
\hline Other & ULK & ULK & 1 & 103838 & Autophagy \\
\hline Other & Uni1 & & 1 & 16436 & Uncharacterized. Lost in plants, fungi, animals \\
\hline Other & VPS15 & & 1 & 113456 & Vesicular transport, autophagy \\
\hline Other & WEE & $\begin{array}{l}\text { WEE- } \\
\text { unclassified }\end{array}$ & 1 & 115572 & Key cell cycle kinase \\
\hline Other & WNK & & 1 & 90343 & Osmotic balance \\
\hline PKL & PIK & FRAP & 1 & 35180 & Metabolic rate control (mTOR/TOR) \\
\hline PKL & PIK & PIK-unclassified & 1 & 16805 & Weakly similar to ATR, but may be a lipid kinase \\
\hline PKL & $\mathrm{RIO}$ & $\mathrm{RIO} 1$ & 1 & 17449 & Ribosome biogenesis \\
\hline PKL & $\mathrm{RIO}$ & $\mathrm{RlO} 2$ & 1 & 5811 & Ribosome biogenesis \\
\hline STE & STE11 & CDC15 & 2 & 16834,6199 & Functions in mitotic exit; lost in plants and holozoans \\
\hline STE & STE11 & $\begin{array}{l}\text { STE11- } \\
\text { unclassified }\end{array}$ & 1 & 1656 & MAP kinase kinase kinase \\
\hline STE & STE20 & FRAY & 1 & 10609 & Not in ciliates, usually co-occurs with Wnk \\
\hline
\end{tabular}


Table 2 Summary of Giardia kinome classification (Continued)

\begin{tabular}{llllll}
\hline STE & STE20 & MST & 1 & 15514 & NDR kinase \\
STE & STE20 & PAKA & 1 & 2796 & Transduces membrane signaling from small GTPases \\
STE & STE20 & YSK & 1 & 14436 & Universal STE20 kinase \\
STE & STE7 & MEK1 & 1 & 22165 & MAP kinase kinase
\end{tabular}

\section{Giardia-specific classes and unique kinases}

\begin{tabular}{|c|c|c|c|c|c|}
\hline Other & Nek & Nek-GL1 & 11 & Table $\mathrm{S} 1^{\mathrm{a}}$ & \\
\hline Other & Nek & Nek-GL2 & 3 & Table $\mathrm{S} 1^{\mathrm{a}}$ & \\
\hline Other & Nek & Nek-GL3 & 4 & Table $S 1^{\mathrm{a}}$ & \\
\hline Other & Nek & Nek-GL4 & 32 & Table $\mathrm{S} 1^{\mathrm{a}}$ & \\
\hline Other & Nek & $\begin{array}{l}\text { Nek- } \\
\text { Unclassified }\end{array}$ & 147 & Table $\mathrm{S} 1^{\mathrm{a}}$ & \\
\hline CMGC & CMGC-GL1 & & 2 & 17139,21116 & Divergent pair of CMGC-like kinases \\
\hline Other & Other-GL1 & & 3 & $\begin{array}{l}17392,17378 \\
6624\end{array}$ & Trio of kinases with no specific homologs \\
\hline Other & $\begin{array}{l}\text { Other- } \\
\text { unique }\end{array}$ & & 8 & Table $\mathrm{S} 1^{\mathrm{a}}$ & Kinases with no specific homologs \\
\hline CMGC & CDK & $\begin{array}{l}\text { CDK- } \\
\text { unclassified }\end{array}$ & 3 & $\begin{array}{l}11290,4191 \\
14578\end{array}$ & Divergent cyclin-dependent kinase \\
\hline CAMK & $\begin{array}{l}\text { CAMK- } \\
\text { unique }\end{array}$ & & 1 & 13852 & Divergent CAMK group member \\
\hline AMK & CAMKL & $\begin{array}{l}\text { CAMKL- } \\
\text { unclassified }\end{array}$ & 2 & 14661,9487 & Divergent CAMKL family member \\
\hline
\end{tabular}

Non-protein kinases from PKL

\begin{tabular}{|c|c|c|c|c|}
\hline CAK & ChoK & 1 & 4596 & Choline and aminoglycoside kinase \\
\hline CAK & FruK & 1 & 2969 & Fructosamine kinase \\
\hline PIK & PI3K & 2 & 14855,17406 & Phosphatidyl inositol 3' kinase \\
\hline PIK & $\mathrm{PI} 4 \mathrm{~K}$ & 1 & 16558 & Phosphatidyl inositol 4' kinase \\
\hline
\end{tabular}

\section{Basal kinases found in Trichomonas, but not Giardia}

$\begin{array}{lll}\text { AGC } & \text { MAST } & \text { MAST } \\ \text { Atypical } & \text { TAF1 } & \\ \text { CAMK } & \text { CDPK } & \\ \text { CK1 } & \text { TTBK } & \\ \text { CMGC } & \text { CDK } & \text { CDK7 } \\ \text { CMGC } & \text { CDK } & \text { CDK12 (CRK7) } \\ \text { CMGC } & \text { DYRK } & \text { YAK } \\ \text { Other } & \text { TLK } & \\ \text { PKL } & \text { PIK } & \text { ATM } \\ \text { PKL } & \text { PIK } & \text { ATR } \\ \text { CMGC } & \text { CDK } & \text { CDK20 (CCRK) }\end{array}$

TKL

\section{Basal kinases found in Leishmania but not Giardia or Trichomonas}

$\begin{array}{lll}\text { PKL } & \text { ABC1 } & \text { ABC1-A } \\ \text { PKL } & A B C 1 & \text { ABC1-B } \\ \text { PKL } & \text { ABC1 } & \text { ABC1-C } \\ \text { HisK } & \text { PDHK } & \text { BCKDK } \\ \text { HisK } & \text { PDHK } & \text { PDHK } \\ \text { CMGC } & \text { DYRK } & \text { DYRKP } \\ \text { PKL } & \text { PIK } & \text { DNAPK }\end{array}$

Mitochondrial kinase

Mitochondrial kinase

Mitochondrial kinase

Mitochondrial kinase

Mitochondrial kinase

Splicing? Also lost in animals, fungi, Dictyostelium

DNA break repair. Absent from fungi, nematodes, insects, some plants
Basal transcriptional machinery, TFIID subunit

Calcium-dependent protein kinase. Lost from unikonts

kinase. Found in unikonts, some chromalveolates, and excavates

Phosphorylates CTD of RNA polymerase ॥

DNA break repair

Cilium-associated, CDK-activating kinase. Found in unikonts, algae, and Trichomonas

Diverse group related to tyrosine kinases 


\begin{tabular}{|c|c|c|c|c|}
\hline \multicolumn{5}{|c|}{ Basal kinases not found in excavates } \\
\hline Other & \multicolumn{3}{|l|}{ IRE } & Endoplasmic reticulum unfolded protein response \\
\hline Other & PEK & \multicolumn{2}{|l|}{ PEK } & Endoplasmic reticulum unfolded protein response. Absent from ciliates \\
\hline Other & NAK & \multicolumn{2}{|l|}{ MPSK } & Secretory pathway function. Absent from ciliates \\
\hline Other & BUB & & & Mitotic spindle checkpoint. Absent from ciliates \\
\hline CMGC & CDK & \multicolumn{2}{|l|}{ CDK8 } & Phosphorylates CTD of RNA polymerase ॥ \\
\hline CMGC & CDK & \multicolumn{2}{|l|}{ CDK11 } & Mitotic spindle function? Absent from fungi \\
\hline CMGC & DYRK & \multicolumn{2}{|l|}{ PRP4 } & Splicing. Lost in fungi \\
\hline PKL & PIK & \multicolumn{2}{|l|}{ SMG1 } & Nonsense-mediated decay of spliced transcripts. Absent from ciliates \\
\hline Hisk & HisK & & & Histidine kinases. Absent from metazoans \\
\hline PKL & Alpha & \multicolumn{2}{|l|}{ WL } & Functions unknown. Absent from metazoans \\
\hline AGC & PKG & & & cGMP-activated protein kinase. Absent from fungi, Dictyostelium \\
\hline PKL & $\mathrm{ABC1}$ & \multirow{2}{*}{\multicolumn{2}{|c|}{$A B C 1-D$}} & Mitochondrial kinase. Absent from ciliates \\
\hline Atypical & G11 & & & Function unknown. Absent from ciliates \\
\hline Other & PLK & \multirow{3}{*}{\multicolumn{2}{|c|}{ SAK }} & Mitotic kinase. Absent from plants \\
\hline Other & Haspin & & & Functions in mitosis. Absent from ciliates \\
\hline AGC & RSK & & & $\begin{array}{l}\text { Ribosomal } \mathbf{S 6} \text { kinase. Excavates lack conserved substrates sites in tail of } \\
\text { ribosomal protein S6 }\end{array}$ \\
\hline CAMK & CAMKL & \multicolumn{2}{|l|}{ MARK } & Microtubule affinity-regulating kinase. Absent from plants \\
\hline \multicolumn{5}{|c|}{ Other kinases shared between excavates and one other ancient group } \\
\hline CAMK & CAMKL & LKB & & $\begin{array}{l}\text { Activator of other CAMKL kinases. Found in excavates and unikonts, lost in } \\
\text { Giardia and L. major }\end{array}$ \\
\hline CAMK & CAMKL & CIPK & 116235 & Found in plants and excavates. CBL-interacting protein kinases \\
\hline CK1 & CK1 & CK1y & & Found in plants and Trichomonas \\
\hline
\end{tabular}

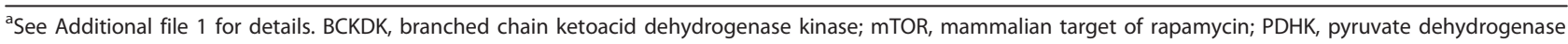
kinase; RSK, ribosomal S6 kinase; TLK, Tousled-like kinase; TOR, target of rapamycin. See Additional file 4 for definitions of other proteins.

on pathway evolution and organismal biology. All three excavates lack 17 kinase classes found in at least two other major eukaryotic groups (unikonts, plants, chromalveolates), suggesting a very early divergence of the excavates [30] and/or even more losses across the

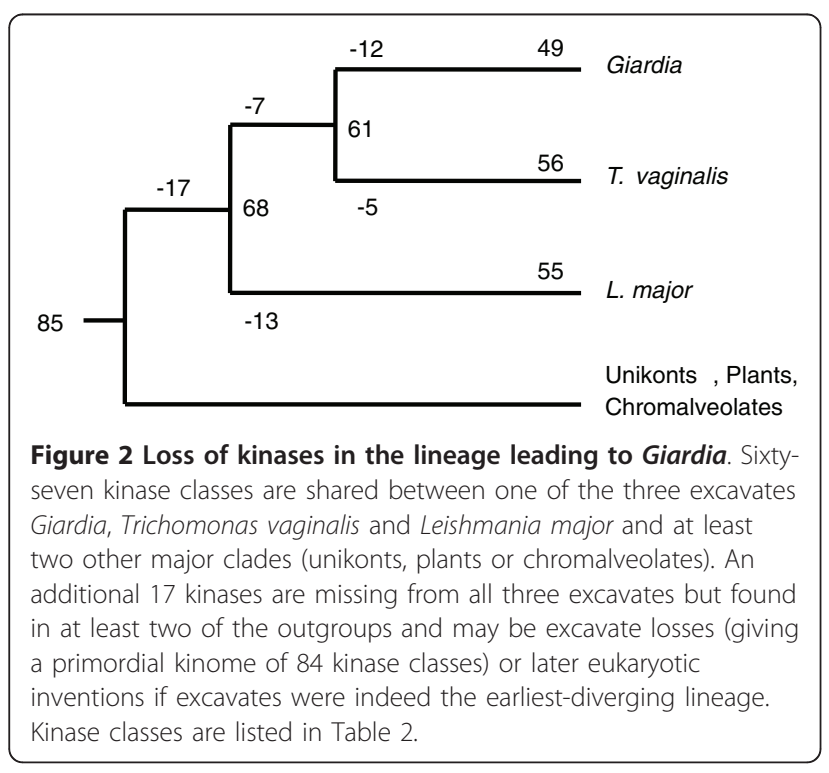

entire clade. This suggests that the common ancestor of extant eukaryotes had 85 different kinase classes (or 68 if excavates are the earliest-diverging clade), substantially more than previous estimates $[19,20]$, and attesting to the many diverse conserved roles of kinases. Several noteworthy themes emerge from these losses (Table 2; see below).

Distinctive patterns of kinase losses in the Giardia lineage Five of the seven ancient kinases lost from Giardia and T. vaginalis, but found in L. major, are mitochondrial kinases (ABC1-A, - B, - C, PDHK, BCKDK), consistent with the degeneration of the mitochondrion to a mitosome or hydrogenosome in these largely anaerobic species [31]. A separate degeneration occurred in some amoebozoa, and accordingly, these kinases are also secondarily lost from Entamoeba histolytica (GM, unpublished). The other two are likely involved in DNA repair and splicing (see below). The 17 kinases found in other early branching lineages but absent from excavates include IRE1 and PEK, which mediate endoplasmic reticulum stress responses, supporting the observed lack of a physiological unfolded protein response in Giardia [32] (see Additional file 4 for definitions of kinase classes discussed in the text). Giardia has unusual dual 
mitotic spindles [33], and all three excavates also lack the spindle-associated kinases BUB and cyclin-dependent kinase (CDK)11. They all also lack the mitosisassociated kinases SAK and Haspin, and their lack of a ribosomal S6 kinase (RSK) correlates with the lack of a regulatory substrate serine in the tail of ribosomal protein S6 in all excavates. Genes lost only from Giardia include three encoding DNA repair kinases (ATR, ATM, TLK) and two RNA polymerase kinases (CDK7, CDK12). Despite having an elaborate microtubule cytoskeleton, Giardia has lost the microtubule-associated kinases MAST and TTBK (Tau tubulin kinase), while microtubule affinity-regulating kinase (MARK) is missing from all excavates. Splicing and RNA-linked kinases DYRKP, YAK, PRP4, and SMG1, and basal transcription factor kinases TAF1 and CDK8 are also lost in different patterns within the excavates, suggesting gradual divergence or reduction in the regulation of these processes.

\section{Losses of DNA repair kinases may explain sensitivity to radiation and chemical DNA damage}

The PIKKs (phosphatidyl inositol 3' kinase-related kinases) ATM, ATR, and DNAPK are involved in recognition and repair of DNA breaks [34]. Deletions of these in several organisms lead to increased radiation and mutagen sensitivity. Giardia is the only eukaryote known to lack all three, though it has one gene (GK009) with very weak similarity to the ATR and ATM kinase domains, yet lacks their conserved accessory domains. Giardia also lacks the Chk1 and Chk2 checkpoint kinases that are activated by ATM and ATR, and the downstream TLK kinases [35]. ATM, ATR, and TLK are all found in T. vaginalis. Giardia does have homologs of other DNA break repair proteins, including MRE11 and RAD50 of the MRN complex, suggesting that aspects of DNA break repair may be functional, but perhaps recognized by a divergent mechanism. Giardia has a single histone $\mathrm{H} 2 \mathrm{~A}$ with a $\mathrm{H} 2 \mathrm{Ax}$-like ATM/ATR substrate site. Induction of double-stranded DNA breaks in trophozoites results in anti-phospho- $\mathrm{H} 2 \mathrm{~A}$ antibody staining [36]. This suggests that some ATM/ATR-like kinase activity may be present, possibly acting through GK009. Giardia also lacks both DNAPK and its binding partners, Ku70 and Ku80, indicating that DNA break repair may be severely diminished or divergent in Giardia. This lack of DNA repair kinases correlates with the reported sensitivity of Giardia cysts to low doses of UV light and inability to repair DNA breaks [37].

\section{Transcription and splicing kinases}

Several CDK family members control RNA polymerase II by phosphorylation of a heptad repeat region in its carboxy-terminal domain (CTD) in plants and animals. These include CDK7, CDK8, CDK9 [38] and CDK12
(CRK7) [39]. Some protists, including ciliates and trypanosomes, lack both the heptad repeat of RNA polymerase II and $C D K 7 / 8 / 9$, but retain $C D K 12$, and several have many Ser-Pro (SP) motifs in the CTD, suggesting that CDK12 may phosphorylate this tail. $T$. vaginalis retains CDK7 and CDK12 and has 19 SP sites in the CTD, while Giardia has only two SP sites and has lost both kinases. CDK12 has also been associated with splicing, which is common in ciliates and trypanosomes, but very rare in Giardia. PRP4 is another splicing-associated kinase lost from Giardia, but other splicing kinases (SRPK, DYRK1, DYRK2) are retained, suggesting that these may have different functions, or be retained for use in the rare cases of Giardia splicing [8].

Giardia also lacks TAF1, an atypical kinase constituent of the general transcription factor TFIID that is known to phosphorylate Ser33 of histone H2B. Giardia $\mathrm{H} 2 \mathrm{~B}$ lacks this serine, and none of the other 13 subunits of TFIID have been identified [40]. TAF1 and several other TFIID complex members are found in T. vaginalis, suggesting loss of this complex from Giardia.

\section{Histidine and tyrosine phosphorylation}

Unlike plants and most protists, Giardia lacks classical histidine kinases. Tyrosine phosphorylation in Giardia trophozoites can be seen by western blot (Figure 3), [11], proteomics (TL, FG, unpublished), and immunofluorescence (Figure 4). However, we found no classical tyrosine kinases (TK group) or members of the related tyrosine kinase-like (TKL) group. A number of other serine-threonine-like kinases have been reported to phosphorylate tyrosine, including Wee1 (cell cycle), MAP2K (though only acting on the MAPK activation loop), and TLK, while DYRK and glycogen synthase kinase (GSK) family kinases can autophosphorylate on tyrosine [41]. Phosphoproteomic profiling of the excavate Trypanosoma brucei shows that more than half of the recorded phosphotyrosine (pTyr) phosphorylation events were found on these kinases [42]. Giardia has one Wee, one MAP2K, one GSK, and four DYRK family kinases. Giardia has no SH2 or PTB phosphotyrosinebinding domains, supporting the lack of a phosphotyrosine signaling system as has been inferred in animals, plants, and Dictyostelium $[20,43]$. By contrast, several proteins with putative phosphoserine or phosphothreonine binding domains are present: two clear forkheadassociated (FHA) domains, one 14-3-3, one WW and over 250 WD40 domains. Of these, only the 14-3-3 protein has been characterized and shown to bind phosphopeptides [44]. Saccharomyces cerevisiae also lacks TK and TKL group kinases, but shows substantial tyrosine phosphorylation by phosphoproteomics [1]. These data from both Saccharomyces and Giardia suggest that 


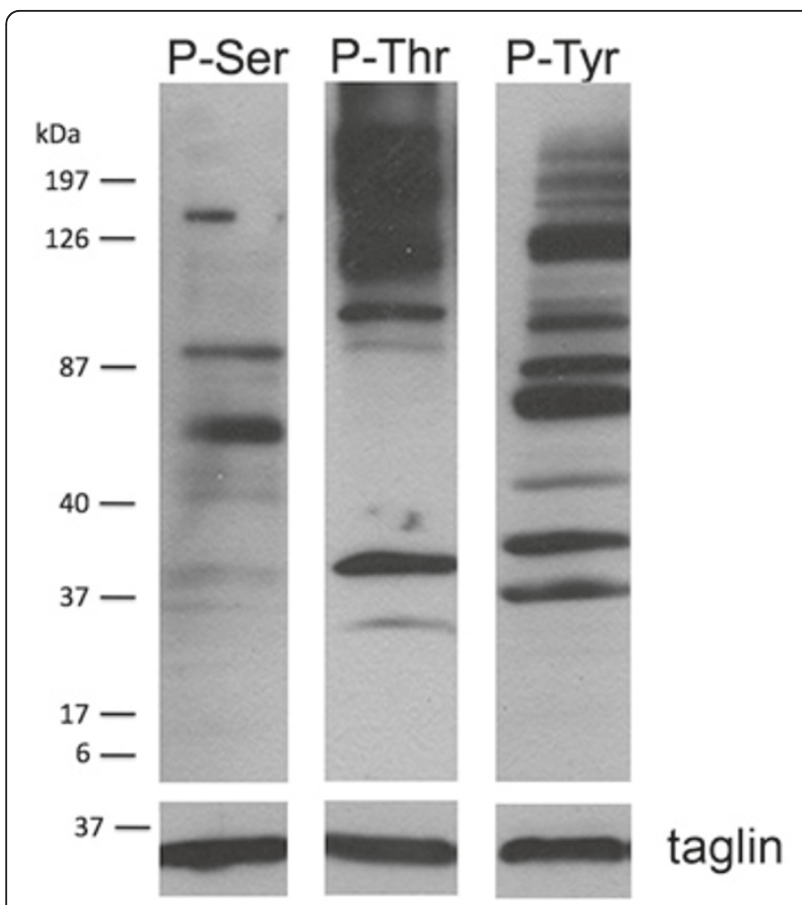

Figure 3 Distribution of serine, threonine and tyrosine phosphorylated proteins. Western blot of total Giardia trophozoite lysates individually labeled with antibodies recognizing phosphoserine (P-Ser), phosphothreonine (P-Thr), or phosphotyrosine (P-Tyr). The taglin loading control is shown at the bottom of the figure.

dual-specificity or undetected tyrosine kinases may be more important than previously thought.

\section{Accessory domains are reduced or divergent}

Most kinases from other genomes have additional domains that help in regulation, localization, or scaffolding. Many core Giardia kinases lack detectable accessory domains. However, the domains that are present correlate well with conserved family-characteristic domains [18]: polo boxes in PLK family kinases; PBD/CRIB domains in PakA; HEAT, FAT and FATC domains in TOR; and pkinase_C in one PKA and one NDR kinase (Additional file 1 ; see Additional file 4 for definitions of domains). Cryptic $\mathrm{PH}$ domains are seen in Akt and PDK1, and the characteristic pkinase_C domain is absent from other AGC kinases, although this can be difficult to detect on such remote sequences. Several other kinases have regions of novel sequence outside of the kinase domain that may be orthologous domains too divergent in sequence to be detectable. No kinase has a clear signal peptide, and only four are predicted to have transmembrane domains. This is consistent with the observed false positive rate for predicting these regions, suggesting that Giardia has no receptor kinases. Other unrelated parasitic protists, including Entamoeba histolytica, have a rich complement of receptor kinases [45]. The Nek kinases are highly enriched for ankyrin repeats and coiled-coil regions (see below).

\section{Catalytically dead kinases}

In most kinomes, about $10 \%$ of kinases lack critical catalytic residues (K72, D166, D184) and are likely to be catalytically inactive, yet may retain signaling functions as scaffolds or kinase substrates [46]. In the WB strain, $10 \%$ ( 8 of 80 ) of the core kinome and $71 \%$ (139 of 195) of Neks lack one or more of these three key residues and are likely to be inactive (Additional file 1). The eight inactive core kinases include Scyl, whose orthologs are all inactive, and Ulk, which has some inactive homologs in other species. The functions of both families in any organism remain obscure. Four pseudokinases are highly divergent proteins specific to Giardia; some might have cryptic active sites that could not be found by alignment to other kinases.

\section{AGC signaling}

The AGC kinase group (PKA/PKG/PKC kinases) mediates a wide variety of intracellular signals, including nutrient, phospholipid and extracellular signal responses. Giardia has seven AGC kinases, including a very divergent PDK1, Akt (GiPKB) [47], two PKAs (cyclic AMP-regulated kinases) $[13,14]$, a lipid flippase kinase (FPK) and two NDR kinases. The $A k t$ and PDK1 genes are particularly divergent, but are partially validated by the presence of weakly predicted phospholipid-binding PH domains, and a likely PDK1 phosphorylation site that is seen in the activation loop of all Giardia AGC kinases. A possible PDK1binding 'hydrophobic motif' is found in Akt (FKDF) and in one NDR kinase (YTYRA), but not in other AGC kinases, and no neighboring phosphorylation site is seen.

Cyclic AMP-dependent signaling is confirmed by the presence of two PKA catalytic subunits (Additional file 1), one regulatory subunit (Orf_9117 in GiardiaDB) [14], and one homolog (Orf_14367) of adenylate and guanylate cyclases. No clear AKAP (A kinase anchoring protein) was found. In many organisms, including Giardia, PKA localizes to the basal bodies/centrosomes [13]. In addition, both the catalytic (PKAc) and regulatory (PKAr) subunits localize to the paraflagellar rods rather than the flagellar axonemes [13,14] (Table 1, Figure 1). PKAc and PKAr localization to the basal bodies is constitutive, while their distribution to the paraflagellar rods is influenced by external stimuli, such as growth factors, encystation stimuli and cAMP levels [13]. Inhibitor studies indicate that PKAc activity is also required for the cellular awakening of excystation [13].

\section{Phospholipid signaling}

The two Giardia phosphatidyl inositol kinases PI3K and one PI4K have been cloned and are expressed in 


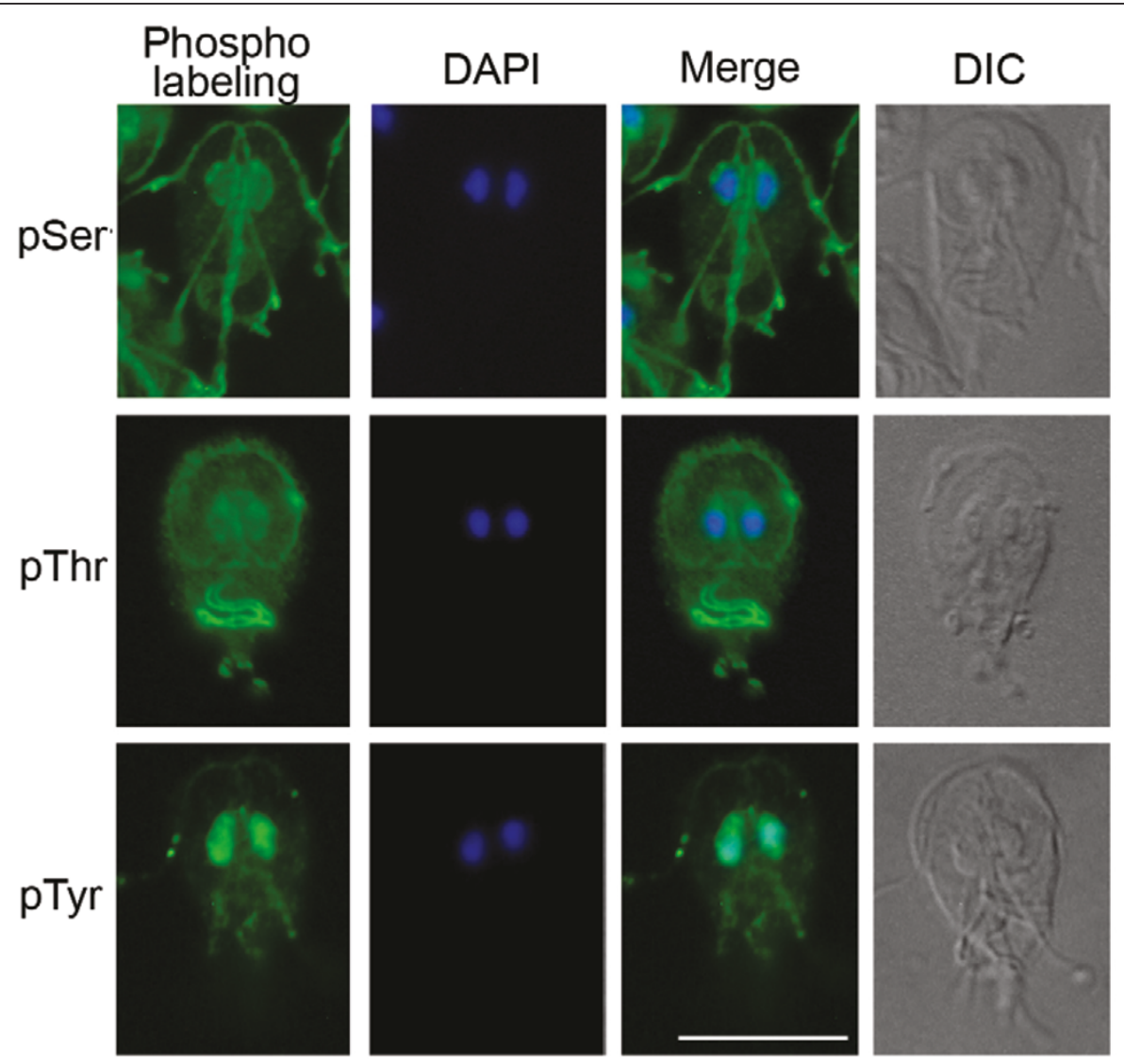

Figure 4 Immunolocalization of serine, threonine and tyrosine phosphorylated proteins in Giardia trophozoites. Interphase trophozoites were labeled with antibodies against phosphoserine (pSer), phosphothreonine (pThr), or phosphotyrosine (pTyr). Phospholabeling is shown in green, nuclei are labeled with DAPI and a merge image shows overlay between the two stains. Morphology is shown in a differential interference contrast $(\mathrm{DIC})$ image of each trophozoite. Scale bar $=10 \mu \mathrm{m}$.

trophozoites and encysting cells [48-50]. As in other species, PI3K likely relays signals from transmembrane receptors by activation of the protein kinase PDK1 to phosphorylate the survival kinase Akt and several other AGC group kinases, as well as the PI3K-like protein kinase TOR, which modulates energy level responses. This suggests that Giardia has intact phospholipid signaling pathways coupled to non-kinase receptors.

\section{MAPK cascade}

The MAPK cascade consists of a relay of up to four kinases that phosphorylate and activate each other, usually to transmit signals from the cell surface to the nucleus. The prototypical MAPK cascade involves the Erk MAPK, which is phosphorylated on both serine and tyrosine by a MAP2K (MEK, MKK, Ste7), which in turn is serine phosphorylated by a MAP3K (MEKK, Ste11), and that by a MAP4K. MAP2K, some MAP3Ks, and MAP4K make up the three families of the STE group of kinases, while Raf and MLK MAP3Ks are from the TKL group. All four kinase classes are found in all analyzed eukaryotic kinomes, apart from Plasmodium [51]. Giardia has one canonical Erk (Erk1), and a member of the distinct Erk7 MAPK subfamily, called Erk2 [16]. Both genes have the MAP2K dual phosphorylation motif ( $\mathrm{T}$ [DE]Y sequence). We found a single MAP2K, along with three MAP3K and four MAP4K genes, one each from the primordial FRAY, MST, PAKA and YSK subfamilies. The single MAP2K indicates either that all the upstream kinases funnel though this single gene, or that there are alternative pathways that bypass MAP2K, for which Giardia may be a tractable model. Two of the three MAP3Ks are homologs of $S$. cerevisiae Cdc15, involved in the mitotic exit network and cytokinesis. These have orthologs in plants and other basal eukaryotes, but not in animals. The distinct functions of Erk1 and Erk 2 are highlighted by their localization: in vegetative trophozoites, Erk1 was found in the disk and median body while Erk2 was in the nuclei and caudal flagella [16] (Figure 1). During encystation, their expression levels remained the same, but their phosphorylation 
and kinase activity were reduced and Erk2 became more cytoplasmic (Table 1).

\section{Cell cycle}

Giardia has a full complement of basic cell cycle kinases (Table 2). These include three CDK1/CDC2 kinases, along with three mitotic (A/B) cyclins, a putative CDK5, three unclassifiable CDKs and two unclassifiable cyclinlike genes, as well as a Wee1 homolog. We also found single copies of the Aurora (AurK) and Polo (PLK) mitotic kinases, which are activated in $M$ phase and involved in centrosome or kinetochore function, spindle assembly and cytokinesis. Giardia AurK is exclusively nuclear during interphase. During mitotic prophase, it is activated by phosphorylation and migrates to the mitotic spindle poles, as well as to the median bodies and anterior paraflagellar rods (PFRs; Figure 1) [52]. Beginning in metaphase, pAurK localizes to the parental attachment disk, which persists until the daughter disks are developed. AurK inhibitors decreased growth and led to abnormal cytokinesis. Thus, AurK has a Giardia-specific localization and likely function in addition to its universal function and location in the mitotic spindle. In mammalian cells, Aur kinase is centrosomal, but interestingly, in Chlamydomonas gametes, it is localized to the flagellar tips or adhesion sites [53].

\section{Expansion and divergence of the Giardia Nek kinase family}

The Nek kinase family is universal in eukaryotes, and its members regulate entry to mitosis [54] and flagellum length $[55,56]$. The Nek family is expanded in both ciliates and excavates, with 40 genes in Tetrahymena and 11 to 25 in trypanosomes [27,57], compared with only 11 in humans and one in yeast. Giardia strain WB has a massive 198 Neks, making up $71 \%$ of its kinome and about $3.7 \%$ of the entire proteome. These have remarkably divergent sequences (Figure 5; Additional file 5); all but 56 have lost critical catalytic residues and are likely pseudokinases, and many show detectable sequence similarity only to other Neks but not to standard kinase domain models. Most retain a number of structural motifs (Additional files 6 and 7), but are so divergent in overall sequence that our count may not be precise.

The Neks are evolutionarily dynamic, accounting for all of the kinase gain and loss between Giardia strains. While $99.7 \%$ of all 4,570 'core' WB genes are found in strains GS and P15 [10], the Neks are one of four families (along with Protein 21.1, HCMP (high cysteine membrane protein) and VSP (variable/variant surface protein) genes) that are both highly expanded and polymorphic between strains, and may be responsible for strain-specific characteristics. Seventy-nine Neks (30\%) are found in only one strain and a further $31(12 \%)$ are found in two but are absent from the third, due to both gene duplication and loss (Additional file 8). Within the Neks, two patterns emerge: most are highly conserved and slowly evolving between strains, while a subset accounts for most of the gene gains and losses.

Of the Neks, 74\% (147 of 198 genes in WB) have no close paralogs (labeled 'Nek-Unclassified'). Their average sequence identity to the next closest Nek is only $34 \%$ in the kinase domain, and for the most divergent $10 \%$ of Neks, this drops to only $20 \%$. This is less than that of orthologous kinase domains between human and Giardia (40\%), and even less than that of many kinases from different families, implying rapid diversification in sequence and function. However, they are well conserved between strains; 89\% (131) have orthologs in all three strains, and their sequences are only slightly less conserved than those of core kinases (average kinase domain identity of $88 \%$ between WB and P15, $78 \%$ between WB and GS, compared with $92 \%$ and $84 \%$ for core kinase domains), indicating that these Neks may be quite ancient, rather than very rapidly evolving.

We classified 51 Neks (26\% of Neks in WB) into 5 subfamilies, based on kinase domain sequence similarity: Nek1, which is conserved throughout eukaryotes, and GL1 to GL4, which are Giardia-specific. GL1 to GL3 are moderately sized subfamilies with 3 to 11 members each. GL4 is dramatically different. It has 32 members in WB, but only 5 of these genes are single copy in each strain. In total, 87 genes across the three strains are not three-way orthologs; 53 of these are found in 10 strainspecific clusters. The rapid turnover of GL4 Neks is further highlighted by our discovery of an additional 30 kinase pseudogenes in the WB strain (these are not counted in the overall kinome), of which 29 are from GL4. Moreover, five pairs of GL4 Neks are very recent duplicates, with over $98 \%$ identity within the pairs. In summary, the Giardia Nek expansion includes both highly divergent but evolutionarily stable members, small and largely stable families, and the GL4 family, which is turning over at a remarkable rate.

Of the Giardia Neks, 67\% (133 of 198) have an amino-terminal kinase domain, followed by a variable array of ankyrin repeats ( 1 to 26 repeats, median of 8), which are not found in any core kinases. They are also evolutionarily mobile, with related members of most subfamilies having gained or lost these repeats. They are divergent in sequence but form a distinctive subclass, characterized by a four amino acid TALM motif at the start and a conserved $\mathrm{E}$ at the end (Additional file 9). Most other Giardia TALM-ankyrin (TA) repeats are found in members of the poorly described Protein 21.1 family, which have a similar structure to Neks but lack the amino-terminal kinase domain. Both families also have some members with coiled-coil regions and 


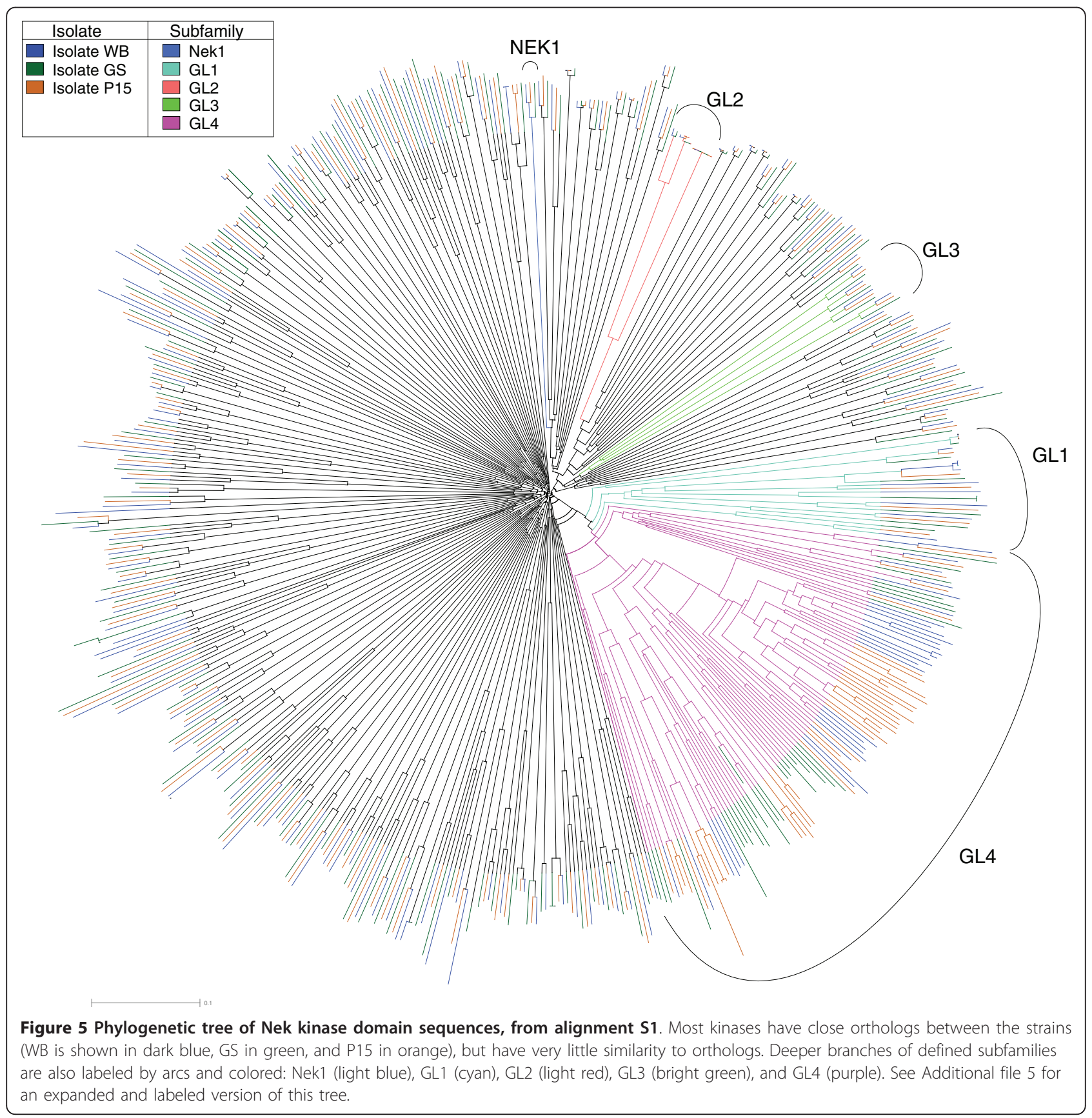

carboxy-terminal RING domains (Additional file 1, Text S1 in Additional file 2), and both are large and evolutionarily dynamic. Our examination of the amino-terminal regions of 21.1 proteins revealed very divergent kinase domains in 20, and cryptic kinase-like domains may exist in other 21.1 proteins that are beyond our limit of confident detection. The TA repeat is largely specific to Giardia: 59\% of the 3,355 Giardia ankyrin repeats have an exact TALM motif, compared with just $2.6 \%$ (54 of $2,028)$ in human and $0.5 \%(24$ of 4,602$)$ in T. vaginalis. Curiously, the only other organism with many TA repeats is the mushroom Coprinopsis cinerea [58], which has 73 proteins containing 271 TA repeats, though none of them have kinase domains. Some are chromosomally clustered, but their functions are unknown (GM, unpublished).

\section{Expression and localization of phosphorylated proteins in Giardia}

Signaling proteins often gain specificity by localization close to their targets. This is especially relevant to Giardia with its unique cytoskeleton that is remodeled 
during differentiation. Moreover, the protein kinases characterized to date localize to distinct cytoskeletal structures that are specific to Giardia and whose functions remain unclear. We characterized major phosphoproteins by western blot and immunofluorescence, using antibodies against phosphoserine (pSer), phosphothreonine (pThr), and pTyr (Figures 3 and 4). Despite the lack of classical tyrosine kinases in Giardia, immunoblots showed strong staining of pTyr, along with pSer and pThr. This corroborates a previous study [11]. Immunofluorescence of Giardia trophozoites with the same antibodies revealed distinct patterns for each phospho-amino acid (Figure 4). Consistent with the predicted absence of receptor kinases in Giardia, we did not observe staining at the plasma membrane. Strong pSer stain was seen in the intracellular and extracellular portions of three of the four pairs of flagellar axonemes (anterior, posterior-lateral, and caudal; Figure 1) as well as the nuclear envelope, with weaker nuclear and ventral flagellar staining. By contrast, pThr most strongly stained the remaining (ventral) pair of flagella, which beat in a sine wave pattern in both attached and swimming trophozoites [6]. It also stained the rim of the ventral attachment disk and polar regions of the nuclei, possibly the nucleoli [59]. In contrast to the largely cytoskeletal localization of pSer and pThr, pTyr staining was concentrated in the nuclei. It is noteworthy that pSer- and pThr-modified proteins tend to localize to the intracellular and extracellular portions of the flagellar axonemes. In contrast, the Ser/Thr kinases in published studies and two of the four Nek kinases tend to localize to intracellular flagellar-associated structures (Figures 1 and 6; see below). Thus, some of the actual phosphorylation may occur in the basal bodies, and the phosphorylated proteins are then incorporated into the flagella.

\section{Expression and localization of individual kinases}

Gene expression profiling by serial analysis of gene expression (SAGE) [60] confirms expression for 233 kinases, including 156 Neks (Additional file 1). Twenty-seven kinases are categorized as differentially expressed throughout the life cycle, of which 12 kinases, all Neks, were upregulated in trophozoites and encyzoites (encysting cells), and 9 Neks and 4 other kinases were selectively expressed in cysts and excyzoites (excysting cells) (Table 3). Overall, Neks are slightly less likely to be expressed than other genes or kinases, and slightly more likely to be differentially or highly expressed, although the differences are not statistically significant. These data suggest that most Neks are expressed and functional, despite their unusual evolution.
To begin to understand the roles of Neks in Giardia, we epitope-tagged five Neks under their own promoters. We observed a different localization pattern for each protein (Figure 6). Orf_5375 (Nek-GL2 subfamily) localized prominently to the PFRs of the anterior and posterior-lateral flagella and faintly to the caudal flagella. Orf_16279 (Nek-Unclassified) localized prominently to the outer half of the ventral attachment disk, to the region of the basal bodies and to the caudal and posterior-lateral flagella, but not to the PFRs. Similarly, Orf_92498 (Nek1) localized to the basal bodies/centrosome region in addition to three pairs of PFRs, as well as to the median bodies, disorganized stacks of microtubules unique to Giardia, whose functions are unknown [6] (Figure 1). Orf_101534 (Nek-GL4) localized to the posterior-lateral PFR and to the perinuclear regions and cytoplasm. In contrast, Orf_15409 (Nek-Unclassified), which has four ankyrin repeats and is catalytically inactive (Additional file 1), localized diffusely to much of the cytoplasm and to an anterior region that may be plasma membrane associated (Figure 6b). Deletion of the most conserved ankyrin repeat of Orf_15409 (amino acids 351 to 386) resulted in partial relocalization to the plasma membrane (Figure 6b).

The distinct localization of these five Neks likely mirrors their specific functions in the different subcellular compartments. Basal body/centrosomal localization of the conserved Nek1 and the Nek-Unclassified is similar to patterns seen in human (Nek2, Nek6, Nek7, and Nek9), Chlamydomonas (Fa2p), Trypanosoma brucei (TbNRKC), and Tetrahymena thermophila (NRK17p and NRK20p) [55,57,61]. The Giardia flagellar basal bodies become spindle poles during mitosis, suggesting that these Neks may be involved in regulating mitotic progression. In other organisms, Neks have also been localized to axonemes. For example, human Nek 8 and Chlamydomonas Fa2p are found in the proximal region of primary cilia or flagella, respectively, and Tetrahymena thermophila NRK1 and NRK30p are located in various types of cilia, with the latter three being involved in regulating flagella/ciliary length $[57,62,63]$. All four active Neks (Orf_5375, Orf_16279, Orf_92498, and Orf_101534) localize to diverse Giardia cytoskeletal structures, and may be involved in regulating flagellar assembly, beat, or cellular attachment [64]. In contrast, the inactive Nek (Orf_15409) is found in the cytoplasm, which may indicate a correlated loss of cytoskeletal association and catalytic activity.

\section{Conclusions}

Giardia encodes the simplest known kinome of any eukaryote that can be grown in axenic culture. Some 
(a)

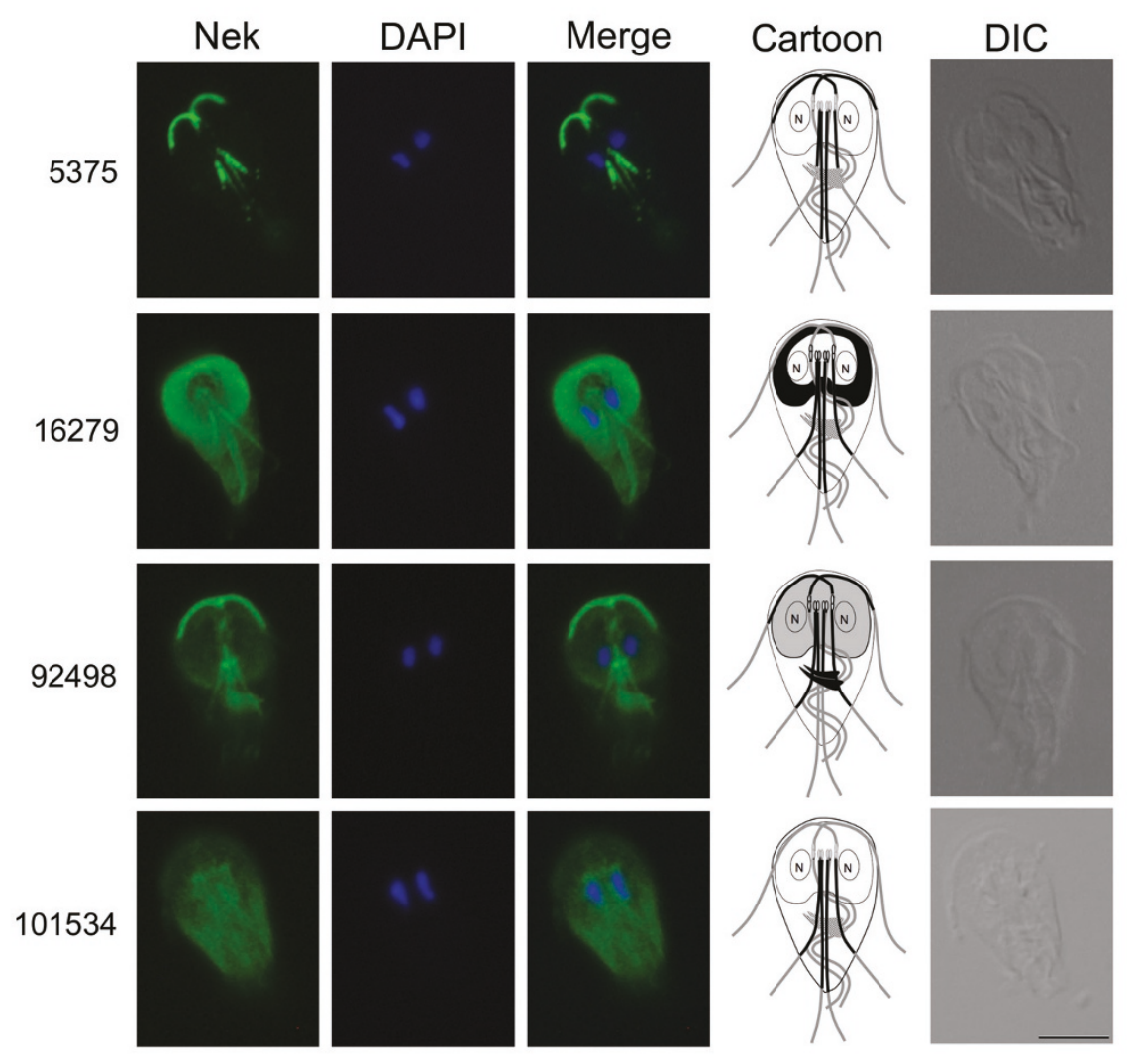

(b)

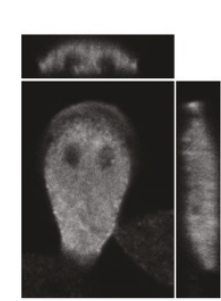

15409

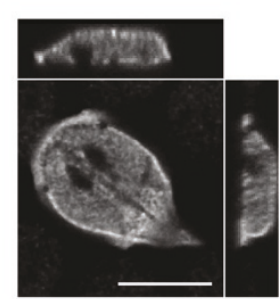

15409 ankyrin deletion

Figure 6 Immunolocalization of Neks in Giardia trophozoites. (a) Giardia trophozoites expressing hemagglutinin (HA)-tagged putative active Neks 5375, 16279, 92498, and 101534 were probed with an anti-hemagglutinin-FITC antibody. Each Nek had a distinct cytoskeletal (5375, 16279, 92498, and 101534) or cytoplasmic (101534) localization pattern. In addition to the PFRs, two Neks localized to the ventral attachment disk and the median bodies (16279 and 92498). A trophozoite cartoon further illustrates each specific Nek localization. Nuclei are labeled with DAPI and a differential interference contrast (DIC) image of each trophozoite is shown on the far right. Scale bar $=5 \mu \mathrm{m}$. (b) Giardia trophozoites expressing full-length Nek 15409 and Nek 15409 with the deleted ankyrin repeat were probed with an anti-AU1 antibody and visualized with confocal microscopy. Z-stack images, shown on top and to the right of each image, show that deletion of the ankyrin repeats altered the distribution of 15409 from solely cytoplasmic to a combination of plasma membrane-associated and cytoplasmic. Scale bar $=5 \mu \mathrm{m}$.

obligate intracellular parasites have even more highly reduced genomes and kinomes (for example, the microsporidian Encephalitozoon cuniculi (29 kinases) [65], and Plasmodium falciparum (approximately 90) [51]), but are dependent on their hosts for many basic cellular functions, and their lost kinases may be functionally replaced by host kinases.

Protein kinases modulate the vast majority of biological pathways, and this minimal kinome still enables Giardia to carry out the broad repertoire of eukaryotic 
Table 3 Differentially expressed kinase transcripts by SAGE

\begin{tabular}{|c|c|c|c|c|c|c|c|c|}
\hline ORF & Group & Family & Subfamily & Orthology & $\begin{array}{l}\text { Catalytically } \\
\text { active? }\end{array}$ & SAGE cluster & $\mathbf{R}$ & $\begin{array}{c}\text { Maximum percentage } \times \\
1,000\end{array}$ \\
\hline 92498 & Other & Nek & $\begin{array}{l}\text { Nek- } \\
\text { Unclassified }\end{array}$ & $1: 1: 1$ & Active & Cysts and excyzoites & 9.56 & 38.5 \\
\hline 17625 & CMGC & GSK & & $1: 1: 1$ & Active & Cysts and excyzoites & 8.30 & 43.4 \\
\hline 8350 & Other & Nek & $\begin{array}{l}\text { Nek- } \\
\text { Unclassified }\end{array}$ & $1: 1: 1$ & Active & Cysts and excyzoites & 9.10 & 44 \\
\hline 14835 & Other & Nek & $\begin{array}{l}\text { Nek- } \\
\text { Unclassified }\end{array}$ & 1:1:1 & Inactive & Cysts and excyzoites & 13.68 & 44 \\
\hline 11364 & AGC & Akt & & $1: 1: 1$ & Active & Cysts and excyzoites & 10.05 & 63.2 \\
\hline 15397 & CMGC & CDK & $\mathrm{CDC2}$ & $1: 1: 1$ & Active & Cysts and excyzoites & 9.46 & 71.5 \\
\hline 8805 & Other & $\mathrm{SCY} 1$ & & $1: 1: 1$ & Inactive & Cysts and excyzoites & 13.93 & 74.3 \\
\hline 17578 & Other & Nek & $\begin{array}{l}\text { Nek- } \\
\text { Unclassified }\end{array}$ & $1: 1: 1$ & Inactive & Cysts and excyzoites & 13.67 & 77 \\
\hline 91451 & Other & Nek & $\begin{array}{l}\text { Nek- } \\
\text { Unclassified }\end{array}$ & $1: 1: 1$ & Active & Cysts and excyzoites & 19.69 & 87.9 \\
\hline 95593 & Other & Nek & Nek-GL2 & $1: 1: 1$ & Active & Cysts and excyzoites & 16.11 & 92.9 \\
\hline 3957 & Other & Nek & $\begin{array}{l}\text { Nek- } \\
\text { Unclassified }\end{array}$ & $1: 1: 1$ & Active & Cysts and excyzoites & 25.71 & 109.9 \\
\hline 114307 & Other & Nek & Nek-GL1 & $1: 1: 1$ & Active & Cysts and excyzoites & 24.87 & 111.5 \\
\hline 22451 & Other & Nek & $\begin{array}{l}\text { Nek- } \\
\text { Unclassified }\end{array}$ & $1: 1: 1$ & Inactive & Cysts and excyzoites & 44.93 & 255.6 \\
\hline 113456 & Other & VPS15 & & $1: 1: 1$ & Active & Differentiation & 9.40 & 75.2 \\
\hline 101307 & Other & Nek & Nek-GL1 & $3: 1: 1$ & Active & $\begin{array}{l}\text { Trophozoites and } \\
\text { encyzoites }\end{array}$ & 10.11 & 37.8 \\
\hline 86934_mod & Other & Nek & Nek-GL1 & $3: 1: 1$ & Active & $\begin{array}{l}\text { Trophozoites and } \\
\text { encyzoites }\end{array}$ & 10.11 & 37.8 \\
\hline 16943 & Other & Nek & $\begin{array}{l}\text { Nek- } \\
\text { Unclassified }\end{array}$ & $1: 1: 1$ & Inactive & $\begin{array}{l}\text { Trophozoites and } \\
\text { encyzoites }\end{array}$ & 11.98 & 39.7 \\
\hline 3677 & Other & Nek & Nek-GL4 & $1: 1: 1$ & Active & $\begin{array}{l}\text { Trophozoites and } \\
\text { encyzoites }\end{array}$ & 10.31 & 54 \\
\hline 113030 & Other & Nek & Nek-GL4 & $1: 1: 1$ & Inactive & $\begin{array}{l}\text { Trophozoites and } \\
\text { encyzoites }\end{array}$ & 10.14 & 59.9 \\
\hline 5346 & Other & Nek & $\begin{array}{l}\text { Nek- } \\
\text { Unclassified }\end{array}$ & $1: 1: 1$ & Active & $\begin{array}{l}\text { Trophozoites and } \\
\text { encyzoites }\end{array}$ & 10.59 & 75.6 \\
\hline 101534 & Other & Nek & Nek-GL4 & C & Active & $\begin{array}{l}\text { Trophozoites and } \\
\text { encyzoites }\end{array}$ & 18.41 & 75.6 \\
\hline 16824 & Other & Nek & $\begin{array}{l}\text { Nek- } \\
\text { Unclassified }\end{array}$ & $1: 1: 1$ & Inactive & $\begin{array}{l}\text { Trophozoites and } \\
\text { encyzoites }\end{array}$ & 8.76 & 81.5 \\
\hline 90343 & Other & WNK & & $1: 1: 1$ & Active & $\begin{array}{l}\text { Trophozoites and } \\
\text { encyzoites }\end{array}$ & 11.42 & 105.2 \\
\hline 114495_mod & Other & Nek & Nek-GL4 & C & Pseudogene & $\begin{array}{l}\text { Trophozoites and } \\
\text { encyzoites }\end{array}$ & 27.04 & 174.5 \\
\hline 24321 & Other & Nek & $\begin{array}{l}\text { Nek- } \\
\text { Unclassified }\end{array}$ & $1: 1: 1$ & Inactive & $\begin{array}{l}\text { Trophozoites and } \\
\text { encyzoites }\end{array}$ & 36.42 & 213.2 \\
\hline 15409 & Other & Nek & $\begin{array}{l}\text { Nek- } \\
\text { Unclassified }\end{array}$ & $1: 0: 2$ & Inactive & $\begin{array}{l}\text { Trophozoites and } \\
\text { encyzoites }\end{array}$ & 35.87 & 507.4 \\
\hline
\end{tabular}

$\mathrm{R}$ is a measure of differential expression, with $\mathrm{R}=8$ used as a cutoff. Max percentage is the percentage of all SAGE tags belonging to this transcript at its maximum level. ORFs 101307 and 86934_mod are almost identical and share the same SAGE tags. Orthology is the number of orthologous kinases in WB:GS:P15; C means a complex ratio.

cellular functions needed for its complex life and cell cycles. Our comparison of the Giardia kinome to other early branching eukaryotes indicates that the last common ancestor of sequenced eukaryotes had a rich kinome of at least 67 kinase classes, from which Giardia has lost at least 18. These include kinases involved in central biological functions, such as DNA repair, transcription, splicing, and mitochondrial metabolism. Exploring how these pathways can function without individual components may help to understand the function of these pathways in more complex organisms.

Other missing kinases, such as those involved in endoplasmic reticulum stress response, are absent from all excavates, and may represent either early losses or 
reflect that excavates are the earliest branching of eukaryotic lineages. Conversely, Giardia retains many ancient kinases (Table 2) whose functions are still largely unexplored, despite their being essential for eukaryotic life.

The Giardia kinome is dominated by the expansion of the Nek kinases. The recurrent loss of kinase catalytic function coupled with the conservation of key structural and Nek-specific residues suggest that many Neks maintain a kinase-like fold and serve as scaffolds. The GL4 subfamily is highly dynamic, with most of its members being strain-specific, with loss of catalytic activity even within a single strain, and showing rampant gene duplication and pseudogenization. This high variation rate may underlie important strain differences. However, the rate of pseudogenization also suggests that the rate of duplication of this gene cluster may be enhanced and that at least some copies are under little purifying selection. By contrast, most other Neks are shared between strains and are likely to be anciently diverged, since their paralogs are more remote than orthologs between human and Giardia. While a homolog of the universal Nek1 was found, the vast majority of Neks are specific to Giardia, and the association with ankyrin repeats is not seen in any other species. The dual mitotic spindles and eight flagella of Giardia may explain some of the Nek expansion, but clearly not all of it. Ciliates are also binucleate and have expanded Neks, but no specific orthologs are found between the two clades, apart from Nek1.

We found long runs of a specific class of ankyrin repeat (TALM-Ankyrin: TA) in most Neks. These are likely important for their subcellular localization or protein interactions. While the four active Neks examined had very specific localization and did not contain ankyrin repeats, the deletion within the ankyrin region in Orf_15409 did alter its localization. Several genes annotated as Protein 21.1 are now found to be Neks, and the overall sequence and domain composition suggests that the Neks and Protein 21.1 genes may form a single family with related functions. The other two large, dynamic Giardia families (VSP and HCMP) are also related to each other and VSPs undergo antigenic variation [66]. However, the roles and reasons for the expansion and variability of HCMP, 21.1 and Nek remain obscure. The arrays of divergent TA repeats and our results with non-ankyrin-containing Neks indicate that specific subcellular targeting is important for their function, and may allow Giardia to regulate complex processes within its single cell by targeting proteins to specific organelles. The Neks constitute a major target for exploration of Giardia-specific and strain-specific biology, and their extreme sequence divergence will be useful to explore the sequence limits of the protein kinase-like fold.
The few published studies and our current work on the first five Nek kinases suggest that several signaling proteins have distinct associations with the PFR, the different flagellar axonemes, or the unique ventral disk and median bodies. The latter, like the basal bodies and flagella, are microtubule-based. Several signaling proteins are shared between the caudal flagella with its associated structures and the disk - Neks 16279 and 92498, ERK1 and PP2Ac (protein phosphatase 2A) - suggesting that they may function in the same signaling pathway.

Understanding the replication and segregation of the two nuclei and complex cytoskeleton during the Giardia cell cycle and life cycle has been challenging [67]. The flagellar basal bodies migrate laterally during mitosis to become spindle poles. Several of the Giardia kinases and phosphatases studied to date localize to the basal bodies during interphase, but most have not yet been studied in mitosis or differentiation (Table 1, Figure 1) and only AurK, PKA and PP2A phosphatase have been partially functionally analyzed. The strong pSer and pThr staining within the flagellar axonemes suggests that substrates may be phosphorylated in the basal bodies before incorporation into the axonemes. Analyses of flagellar-associated kinases and signaling may help better understand the roles of the four flagellar pairs in Giardia swimming, attachment, and detachment, which are central to disease [68], as well as to better understand the roles of this almost universal organelle.

Taken together, our data may help to prioritize future functional kinase studies, elucidate the signaling underlying the cell and life cycles and provide new drug targets to treat Giardia infections. Protein kinases are proven drug targets, and the high divergence of Giardia sequences suggests that specific inhibitors could be developed that have minimal activity against human kinases. Our findings help define the minimal kinase complement of a single-celled eukaryote with a complex life and cell cycle and add to our understanding of Giardia biology, pathogenesis, and evolution.

\section{Materials and methods}

\section{Software, data sets and databases}

The G lamblia genome assemblies for all three strains were from release 2.3 of GiardiaDB [69]. Sequenced strains are from ATCC, accession numbers 50803 (assemblage A, WB clone C6), 50581 (assemblage B, clone GS) and GLP15 (assemblage E, clone p15). T. vaginalis sequences were from release 1.2 of TrichDB [70], and L. major from release 2.5 of TriTrypDB [71].

\section{Sequence analysis}

We constructed profile HMMs for the ePK, PIKK, RIO, $\mathrm{ABC} 1, \mathrm{PDK}$, and alpha-kinase families with HMMer and used these to search the ORF, genomic, and EST 
sequences using Decypher hardware-accelerated HMMer implementation from Time Logic (Carlsbad, CA, USA). Divergent Neks were identified with several Nek-specific HMMs and Blast searches, followed by manual inspection for conserved kinase motifs. Final predicted kinase sequences were searched against the Pfam HMM profiles, using both local and glocal models. All matches with $\mathrm{P}$ scores $<0.01$ were accepted and all matches with scores of 0.01 to 1.0 were evaluated in comparison with known, homologous sequences, inspection of the domain alignment, and reference to the literature. L. major sequences were classified in part using psi-blast with orthologous sequences from other kinetoplastids, and T. vaginalis expansions were also classified using psi-blast profiles built from paralogs. Signal peptides were detected using SignalP and transmembrane regions using TM-HMM [72] and coiled-coil domains according to Lupas et al. [73]. Nek kinase domains were aligned with ClustalW [74] and HMMalign [75], and then extensively edited by hand using JalView [76]. The Nek tree was built using the ClustalW neighbor-joining algorithm and colored by hand using Adobe Illustrator.

\section{Cultivation of Giardia}

G. lamblia trophozoites (strain WB, clone C6, ATCC 50803) were cultured in modified TYI-S-33 medium with bovine bile $[77,78]$.

\section{Western blot}

Cells were washed with ice cold PBS and cell proteins were precipitated in 6\% TCA (trichloroacetic acid) for 2 hours on ice. Protein pellets were resuspended in reducing SDS-PAGE sample buffer, neutralized with $\mathrm{NaOH}$, boiled for 5 minutes and stored at $-80^{\circ} \mathrm{C}$ until use. Protein concentrations were determined by the Bradford method (Biorad, Hercules, CA, USA). Proteins were separated by 4-20\% SDS PAGE and transferred to PVDF filters. Filters were blocked with $1 \%$ milk in PBS supplemented with $0.1 \%$ Tween 20 (PBS-Tween) and incubated for 1 hour with the FITC-labeled mouse monoclonal antibodies against pSer, pThr or pTyr (Sigma, St. Louis, MO, USA) in 1\% milk. Blots were then washed four times with PBS-Tween and incubated with secondary antibody (goat anti-mouse-horse radish peroxidase (HRP)) for 1 hour. The signal was developed with ECL-plus (GE Healthcare, Waukesha, WI, USA). As a protein loading control, blots were reprobed with the mouse monoclonal anti-taglin antibody [79] and goat anti-mouse-HRP. As a control for antibody specificity, antibodies were incubated with pSer, pThr or pTyr conjugated to bovine serum albumin (Sigma), respectively, prior to immunolabeling of filters. As an additional control, total Giardia lysates were dephosphorylated with protein phosphatase $\lambda$ (New
England Biolabs, Ipswich, MA, USA) according to the manufacturer's protocol. Both controls eliminated signal on western blot, confirming specificity of the antibodies (data not shown).

\section{Epitope tagging of proteins}

The region containing the promoter (> 100 base pairs upstream of the start codon) and coding sequences for Orf_5375 were amplified from G. lamblia strain WB clone C6 (ATCC 50803) genomic DNA with the primers 5'-taagggcccagcatctagctgaatgccga-3' and 5'-taagatatccatcttatacttgtaagcgcc-3', Orf_92498 with primers 5'gggccccggatgcgcgtctgttg-3' and 5'-gatatccctgacagtattgaacctgtcc-3', Orf_16279 with primers 5'-gggcccggatccgaggtcatgcgc-3' and 5'-gatatcagaaaggcgtctctgcgtcaaaac-3', Orf_101534 with primers 5'-gggcccggcctgactgcgcatgc-3' and 5'-gatatcctgtctgagcatctcgcacagc-3', and Orf_15409 with primers 5'-tttaagcttccctgccgctgagtgaacat-3' and 5'tttgggcccaggttcaggacctcacgcac-3'. The PCR products and the vector encoding the carboxy-terminal AU1 tag (Orf_15409) [80] or HA tag (all other Neks) [81] were digested with the respective restriction enzymes. Digested inserts and vectors were gel extracted using a QIAquick Gel Extraction Kit (Qiagen, Venlo, The Netherlands), and ligated overnight at $14^{\circ} \mathrm{C}$. Plasmids were transformed into Escherichia coli JM109 (Promega, Fitchburg, WI, USA \}). Bacteria were grown overnight in Luria broth and plasmid DNA was purified using a Maxiprep kit (Qiagen) and sequenced (Etonbio, San Diego, CA, USA\}). Trophozoites were electroporated with $50 \mu \mathrm{g}$ plasmid DNA and transfectants were maintained through puromycin selection [82]. Base pairs 1.051 to 1,158 from the ankyrin repeat region of Orf_15409 were deleted by linking the upstream and downstream PCR products together with the internal primers 5'-agtccacatgtactggtctgtggacctgcctggtg-3' and 5'-tccacagaccagtacatgtggactgcaaccatgtat-3'.

\section{Immunofluorescence analysis}

Trophozoites were harvested by chilling and allowed to adhere to coverslips at $37^{\circ} \mathrm{C}$ for 10 minutes. Whole trophozoites were fixed in situ with methanol $\left(-20^{\circ} \mathrm{C}\right)$, permeabilized for 10 minutes with $0.5 \%$ Triton $\mathrm{X}-100$ in PBS [13] and blocked for 1 hour in 5\% goat serum, 1\% glycerol, $0.1 \%$ bovine serum albumin, $0.1 \%$ fish gelatin and $0.04 \%$ sodium azide. Coverslips were subsequently incubated for 1 hour with the FITC-labeled mouse monoclonal antibodies against pSer, pThr or pTyr (Sigma) or with the rat anti-HA-FITC (Roche, Indianapolis, IN, USA). Cells that were expressing AU1-tagged Nek (Orf_15409) were incubated with the primary antibody mouse anti-AU1 for 1 hour, washed four times over 20 minutes, and incubated with the goat antimouse Alexa 488 secondary antibody (Invitrogen, 
Carlsbad, CA, USA). Coverslips were washed, postfixed with $4 \%$ paraformaldehyde, rinsed with PBS and mounted with Prolong Gold with DAPI (Molecular Probes, Eugene, OR, USA). As a control for antibody specificity, antibodies were incubated with pSer-, pThror pTyr-labeled albumin (Sigma), respectively, prior to immunolabeling. Staining was monitored and photographed on a Nikon Eclipse E800 microscope with an $\mathrm{X}$-Cite ${ }^{\mathrm{TM}} 120$ fluorescence lamp and 1,000 $\times$ magnification (Nikon Instruments Inc.). Confocal images were taken with the Leica TCS SP5 system attached to a DMI 6000 inverted microscope (Leica).

\section{Additional material}

Additional file 1: Table S1. Detailed annotation of all kinases in all three strains, including sequences, SAGE expression, classification, and catalytic ability.

Additional file 2: Text S1. Supplemental methods and notes.

Additional file 3: Table S2. Draft kinomes of Trichomonas vaginalis and Leishmania major.

Additional file 4: Table S3. Definition of domain names and abbreviations.

Additional file 5: Figure S4. Nek kinase tree, colored and annotated. Additional file 6: Alignment S1. Nek kinase domain alignment. Additional file 7: Figure S1. Logo alignment comparing patterns of conserved residues in Giardia and non-Giardia Neks.

Additional file 8: Figure S2. Tree of Nek kinases showing gains and losses between strains.

Additional file 9: Figure S3. Logo alignment comparing patterns of conserved residues in Giardia TALM-ankyrin repeats and human ankyrin repeats.

\section{Abbreviations}

CDK: cyclin-dependent kinase; DAPI: 4',6-diamidino-2-phenylindole; DNAPK: DNA protein kinase; EST: expressed sequence tag; FITC: fluorescein isothiocyanate; GSK: glycogen synthase kinase; HA: hemagglutinin; HCMP: high cysteine membrane protein; HMM: hidden Markov model; MAPK: mitogen-activated protein kinase; ORF: open reading frame; PBS: phosphatebuffered saline; PFR: paraflagellar rods; PIK: phosphatidyl inositol kinase; PIKK: phosphatidyl inositol 3' kinase-related kinase; PK: protein kinase; pSer: phosphoserine; pThr: phosphothreonine; pTyr: phosphotyrosine; SAGE: serial analysis of gene expression; SP: Ser-Pro; TA: TALM-ankyrin; TK: tyrosine kinase; TKL: tyrosine kinase-like; TOR: target of rapamycin; VSP: variant-specific surface protein.
\end{abstract}

\section{Acknowledgements}

This work was supported by NIH grants, Al42488, Al51687 and Al75527 (FG), and R01 HG004164 and P30 CA014195 (GM). AJS was supported by Gl Training grant T32DK07202. We thank T Hunter and members of the Manning lab for critical reading of the manuscript. We are grateful to $H$ Ward for the antibody to taglin. All sequence analysis presented here and additional supporting evidence are freely available at KinBase [18]. Sequences and other annotations are from GiardiaDB [69].

\section{Author details}

'Razavi Newman Center for Bioinformatics, The Salk Institute for Biological Studies, 10010 North Torrey Pines Road, La Jolla, CA 92037, USA. ${ }^{2}$ Department of Pathology, University of California at San Diego, 214 Dickinson St CTF-C 415, San Diego, CA 92103-8416, USA. ${ }^{3}$ Department of Microbiology, Tumor and Cell Biology (MTC), Nobels väg 16, KI Solna
Campus, Karolinska Institutet, Box 280, SE-171 77, Stockholm, Sweden ${ }^{4}$ Current address: Proveri Inc., 10835 Road to the Cure, Suite 150, San Diego, CA 92121, USA. ${ }^{5}$ Department of Cell and Molecular Biology, Uppsala University, BMC, Box 596, SE-75124, Uppsala, Sweden.

\section{Authors' contributions}

FDG, GM, DSR, and SS conceived of the study, including its design and coordination. GM and FDG wrote the manuscript with contributions from $T L$, $A S$, and MD. DSR cataloged the initial WB kinome, and MD, GM, and YZ carried out extensive curation and computational and phylogenetic analysis of all five kinomes. TL performed the immunoblot identification and immunolocalization of phosphorylated proteins (Figures 3 and 4). TL and AS carried out the molecular genetic and cell biologic studies of the Nek kinases and prepared Figures 1 and 3 to 5 and Table 1. All authors contributed to the editing of the manuscript.

Received: 24 December 2010 Revised: 4 May 2011

Accepted: 25 July 2011 Published: 25 July 2011

\section{References}

1. Holt $\amalg$, Tuch BB, Villen J, Johnson AD, Gygi SP, Morgan DO: Global analysis of Cdk1 substrate phosphorylation sites provides insights into evolution. Science 2009, 325:1682-1686.

2. Adam RD: Biology of Giardia lamblia. Clin Microbiol Rev 2001, 14:447-475.

3. Bingham AK, Meyer EA: Giardia excystation can be induced in vitro in acidic solutions. Nature 1979, 277:301-302.

4. Boucher SE, Gillin FD: Excystation of in vitro-derived Giardia lamblia cysts. Infec Immun 1990, 58:3516-3522.

5. Bernander R, Palm JE, Svard SG: Genome ploidy in different stages of the Giardia lamblia life cycle. Cell Microbiol 2001, 3:55-62.

6. Elmendorf HG, Dawson SC, MCCaffery JM: The cytoskeleton of Giardia lamblia. Int J Parasitol 2003, 33:3-28.

7. Dawson SC, House SA: Life with eight flagella: flagellar assembly and division in Giardia. Curr Opin Microbiol 2010, 13:480-490.

8. Morrison HG, McArthur AG, Gillin FD, Aley SB, Adam RD, Olsen GJ, Best AA, Cande WZ, Chen F, Cipriano MJ, Davids BJ, Dawson SC, Elmendorf HG, Hehl AB, Holder ME, Huse SM, Kim UU, Lasek-Nesselquist E, Manning G, Nigam A, Nixon JE, Palm D, Passamaneck NE, Prabhu A, Reich Cl, Reiner DS, Samuelson J, Svard SG, Sogin ML: Genomic minimalism in the early diverging intestinal parasite Giardia lamblia. Science 2007, 317:1921-1926.

9. Franzen O, Jerlstrom-Hultqvist J, Castro E, Sherwood E, Ankarklev J, Reiner DS, Palm D, Andersson JO, Andersson B, Svard SG: Draft genome sequencing of Giardia intestinalis assemblage B isolate GS: is human Giardiasis caused by two different species? PLoS Pathog 2009, 5:e1000560

10. Jerlstrom-Hultqvist J, Franzen O, Ankarklev J, Xu F, Nohynkova E, Andersson JO, Svard SG, Andersson B: Genome analysis and comparative genomics of a Giardia intestinalis assemblage $\mathrm{E}$ isolate. BMC Genomics 2010, 11:543.

11. Parsons $\mathrm{M}$, Valentine $\mathrm{M}$, Carter V: Protein kinases in divergent eukaryotes: identification of protein kinase activities regulated during trypanosome development. Proc Natl Acad Sci USA 1993, 90:2656-2660.

12. Alvarado ME, Wasserman M: Analysis of phosphorylated proteins and inhibition of kinase activity during Giardia intestinalis excystation. Parasitol Int 2010, 59:54-61.

13. Abel ES, Davids BJ, Robles LD, Loflin CE, Gillin FD, Chakrabarti R: Possible roles of protein kinase $A$ in cell motility and excystation of the early diverging eukaryote Giardia lamblia. J Biol Chem 2001, 276:10320-10329.

14. Gibson C, Schanen B, Chakrabarti D, Chakrabarti R: Functional characterisation of the regulatory subunit of cyclic AMP-dependent protein kinase A homologue of Giardia lamblia: differential expression of the regulatory and catalytic subunits during encystation. Int J Parasitol 2006, 36:791-799.

15. Lauwaet T, Davids BJ, Torres-Escobar A, Birkeland SR, Cipriano MJ, Preheim SP, Palm D, Svard SG, McArthur AG, Gillin FD: Protein phosphatase 2A plays a crucial role in Giardia lamblia differentiation. Mol Biochem Parasitol 2007, 152:80-89.

16. Ellis JGt, Davila M, Chakrabarti R: Potential involvement of extracellular signal-regulated kinase 1 and 2 in encystation of a primitive eukaryote, Giardia lamblia. Stage-specific activation and intracellular localization. $J$ Biol Chem 2003, 278:1936-1945. 
17. Aurrecoechea C, Brestelli J, Brunk BP, Carlton JM, Dommer J, Fischer S, Gajria B, Gao X, Gingle A, Grant G, Harb OS, Heiges M, Innamorato F, lodice J, Kissinger JC, Kraemer E, Li W, Miller JA, Morrison HG, Nayak V, Pennington C, Pinney DF, Roos DS, Ross C, Stoeckert CJ Jr, Sullivan S, Treatman C, Wang H: GiardiaDB and TrichDB: integrated genomic resources for the eukaryotic protist pathogens Giardia lamblia and Trichomonas vaginalis. Nucleic Acids Res 2009, 37:D526-530.

18. KinBase. [http://kinase.com/kinbase/].

19. Eisen JA, Coyne RS, Wu M, Wu D, Thiagarajan M, Wortman JR, Badger JH, Ren Q, Amedeo P, Jones KM, Tallon L, Delcher AL, Salzberg SL, Silva JC, Haas BJ, Majoros WH, Farzad M, Carlton JM, Smith RK Jr, Garg J, Pearlman RE, Karrer KM, Sun L, Manning G, Elde NC, Turkewitz AP, Asai DJ,

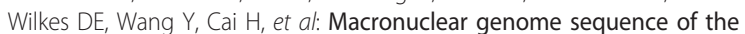
ciliate Tetrahymena thermophila, a model eukaryote. PLoS Biol 2006, 4 : e286.

20. Goldberg JM, Manning G, Liu A, Fey P, Pilcher KE, Xu Y, Smith JL: The Dictyostelium kinome-analysis of the protein kinases from a simple model organism. PLoS Genet 2006, 2:e38.

21. Manning G, Plowman GD, Hunter T, Sudarsanam S: Evolution of protein kinase signaling from yeast to man. Trends Biochem Sci 2002, 27:514-520.

22. Manning $G$, Whyte $D B$, Martinez $R$, Hunter $T$, Sudarsanam $S$ : The protein kinase complement of the human genome. Science 2002, 298:1912-1934

23. Banks Jea: The compact Selaginella genome identifies changes in gene content associated with the evolution of vascular plants. Science 2011, 332:960-963.

24. Bazan-Tejeda ML, Arguello-Garcia R, Bermudez-Cruz RM, Robles-Flores M, Ortega-Pierres G: Protein kinase C isoforms from Giardia duodenalis: identification and functional characterization of a beta-like molecule during encystment. Arch Microbiol 2007, 187:55-66.

25. Lujan HD, Mowatt MR, Helman LJ, Nash TE: Insulin-like growth factors stimulate growth and L-cysteine uptake by the intestinal parasite Giardia lamblia. J Biol Chem 1994, 269:13069-13072.

26. Carlton JM, Hirt RP, Silva JC, Delcher AL, Schatz M, Zhao Q, Wortman JR, Bidwell SL, Alsmark UC, Besteiro S, Sicheritz-Ponten T, Noel CJ, Dacks JB, Foster PG, Simillion C, Van de Peer Y, Miranda-Saavedra D, Barton GJ, Westrop GD, Muller S, Dessi D, Fiori PL, Ren Q, Paulsen I, Zhang H, BastidaCorcuera FD, Simoes-Barbosa A, Brown MT, Hayes RD, Mukherjee M, et al: Draft genome sequence of the sexually transmitted pathogen Trichomonas vaginalis. Science 2007, 315:207-212.

27. Naula C, Parsons M, Mottram JC: Protein kinases as drug targets in trypanosomes and Leishmania. Biochim Biophys Acta 2005, 1754:151-159

28. Baldauf SL: The deep roots of eukaryotes. Science 2003, 300:1703-1706.

29. Ankarklev J, Jerlstrom-Hultqvist J, Ringqvist E, Troell K, Svard SG: Behind the smile: cell biology and disease mechanisms of Giardia species. Nat Rev 2010, 8:413-422

30. Hampl V, Hug L, Leigh JW, Dacks JB, Lang BF, Simpson AG, Roger AJ: Phylogenomic analyses support the monophyly of Excavata and resolve relationships among eukaryotic "supergroups". Proc Natl Acad Sci USA 2009, 106:3859-3864

31. Regoes A, Zourmpanou D, Leon-Avila G, van der Giezen M, Tovar J, Hehl AB: Protein import, replication, and inheritance of a vestigial mitochondrion. J Biol Chem 2005, 280:30557-30563.

32. Reiner DS, McCaffery JM, Gillin FD: Reversible interruption of Giardia lamblia cyst wall protein transport in a novel regulated secretory pathway. Cell Microbiol 2001, 3:459-472.

33. Sagolla MS, Dawson SC, Mancuso JJ, Cande WZ: Three-dimensional analysis of mitosis and cytokinesis in the binucleate parasite Giardia intestinalis. J Cell Sci 2006, 119:4889-4900.

34. Yang J, Yu Y, Hamrick HE, Duerksen-Hughes PJ: ATM, ATR and DNA-PK: initiators of the cellular genotoxic stress responses. Carcinogenesis 2003, 24:1571-1580.

35. Groth A, Lukas J, Nigg EA, Sillje HH, Wernstedt C, Bartek J, Hansen K: Human Tousled like kinases are targeted by an ATM- and Chk1dependent DNA damage checkpoint. EMBO J 2003, 22:1676-1687.

36. Hofstetrova K, Uzlikova M, Tumova P, Troell K, Svard SG, Nohynkova E: Giardia intestinalis: aphidicolin influence on the trophozoite cell cycle. Exp Parasitol 2010, 124:159-166

37. Linden KG, Shin GA, Faubert G, Cairns W, Sobsey MD: UV disinfection of Giardia lamblia cysts in water. Environ Sci Technol 2002, 36:2519-2522.
38. Guo Z, Stiller JW: Comparative genomics and evolution of proteins associated with RNA polymerase II C-terminal domain. Mol Biol Evol 2005, 22:2166-2178

39. Lee JM, Greenleaf AL: CTD kinase large subunit is encoded by CTK1, a gene required for normal growth of Saccharomyces cerevisiae. Gene Expression 1991, 1:149-167.

40. Best AA, Morrison HG, McArthur AG, Sogin ML, Olsen GJ: Evolution of eukaryotic transcription: insights from the genome of Giardia lamblia. Genome Res 2004, 14:1537-1547.

41. Wikinome: Dual Specificity Kinases. [http://kinase.com/wiki/index.php/ Dual-Specificity_Kinases].

42. Nett IR, Martin DM, Miranda-Saavedra D, Lamont D, Barber JD, Mehlert A, Ferguson MA: The phosphoproteome of bloodstream form Trypanosoma brucei, causative agent of African sleeping sickness. Mol Cell Proteomics 2009, 8:1527-1538.

43. Manning G, Young SL, Miller WT, Zhai Y: The protist, Monosiga brevicollis, has a tyrosine kinase signaling network more elaborate and diverse than found in any known metazoan. Proc Natl Acad Sci USA 2008, 105:9674-9679.

44. Lalle M, Salzano AM, Crescenzi M, Pozio E: The Giardia duodenalis 14-3-3 protein is post-translationally modified by phosphorylation and polyglycylation of the C-terminal tail. J Biol Chem 2006, 281:5137-5148.

45. Anamika K, Bhattacharya A, Srinivasan N: Analysis of the protein kinome of Entamoeba histolytica. Proteins 2008, 71:995-1006.

46. Scheeff ED, Eswaran J, Bunkoczi G, Knapp S, Manning G: Structure of the pseudokinase VRK3 reveals a degraded catalytic site, a highly conserved kinase fold, and a putative regulatory binding site. Structure 2009, 17:128-138.

47. Kim KT, Mok MT, Edwards MR: Protein kinase B from Giardia intestinalis. Biochem Biophys Res Commun 2005, 334:333-341.

48. Hernandez Y, Zamora G, Ray S, Chapoy J, Chavez E, Valvarde R, Williams E, Aley SB, Das S: Transcriptional analysis of three major putative phosphatidylinositol kinase genes in a parasitic protozoan, Giardia lamblia. J Eukaryot Microbiol 2007, 54:29-32.

49. Cox SS, van der Giezen M, Tarr SJ, Crompton MR, Tovar J: Evidence from bioinformatics, expression and inhibition studies of phosphoinositide-3 kinase signalling in Giardia intestinalis. BMC Microbiol 2006, 6:45.

50. Morrison HG, Zamora G, Campbell RK, Sogin ML: Inferring protein function from genomic sequence: Giardia lamblia expresses a phosphatidylinositol kinase-related kinase similar to yeast and mammalian TOR. Comp Biochem Physiol B Biochem Mol Biol 2002, 133:477-491

51. Ward P, Equinet $L$, Packer J, Doerig C: Protein kinases of the human malaria parasite Plasmodium falciparum: the kinome of a divergent eukaryote. BMC Genomics 2004, 5:79.

52. Davids BJ, Williams S, Lauwaet T, Palanca T, Gillin FD: Giardia lamblia aurora kinase: a regulator of mitosis in a binucleate parasite. Int $J$ Parasitol 2008, 38:353-369.

53. Pan J, Snell WJ: Regulated targeting of a protein kinase into an intact flagellum. An aurora/lpl1p-like protein kinase translocates from the cell body into the flagella during gamete activation in chlamydomonas. $J$ Biol Chem 2000, 275:24106-24114.

54. O'Connell MJ, Krien MJ, Hunter T: Never say never. The NIMA-related protein kinases in mitotic control. Trends Cell Biol 2003, 13:221-228.

55. Mahjoub MR, Qasim Rasi M, Quarmby LM: A NIMA-related kinase, Fa2p, localizes to a novel site in the proximal cilia of Chlamydomonas and mouse kidney cells. Mol Biol Cell 2004, 15:5172-5186.

56. Liu S, Lu W, Obara T, Kuida S, Lehoczky J, Dewar K, Drummond IA, Beier DR: A defect in a novel Nek-family kinase causes cystic kidney disease in the mouse and in zebrafish. Development 2002, 129:5839-5846.

57. Wloga D, Camba A, Rogowski K, Manning G, Jerka-Dziadosz M, Gaertig J: Members of the NIMA-related kinase family promote disassembly of cilia by multiple mechanisms. Mol Biol Cell 2006, 17:2799-2810.

58. Stajich JE, Wilke SK, Ahren D, Au CH, Birren BW, Borodovsky M, Burns C, Canback B, Casselton LA, Cheng CK, Deng J, Dietrich FS, Fargo DC, Farman ML, Gathman AC, Goldberg J, Guigo R, Hoegger PJ, Hooker JB, Huggins A, James TY, Kamada T, Kilaru S, Kodira C, Kues U, Kupfer D, Kwan HS, Lomsadze A, Li W, Lilly WW, et al: Insights into evolution of multicellular fungi from the assembled chromosomes of the mushroom Coprinopsis cinerea (Coprinus cinereus). Proc Natl Acad Sci USA 2010, 107:11889-11894. 
59. Jimenez-Garcia LF, Zavala G, Chavez-Munguia B, Ramos-Godinez Mdel P Lopez-Velazquez G, Segura-Valdez Mde L, Montanez C, Hehl AB, ArguelloGarcia R, Ortega-Pierres G: Identification of nucleoli in the early branching protist Giardia duodenalis. Int J Parasitol 2008, 38:1297-1304.

60. Birkeland SR, Preheim SP, Davids BJ, Cipriano MJ, Palm D, Reiner DS, Svard SG, Gillin FD, McArthur AG: Transcriptome analyses of the Giardia lamblia life cycle. Mol Biochem Parasitol 2010, 174:62-65.

61. Pradel LC, Bonhivers M, Landrein N, Robinson DR: NIMA-related kinase TbNRKC is involved in basal body separation in Trypanosoma brucei. J Cell Sci 2006, 119:1852-1863.

62. Shiba D, Manning DK, Koga H, Beier DR, Yokoyama T: Inv acts as a molecular anchor for Nphp3 and Nek8 in the proximal segment of primary cilia. Cytoskeleton 2010, 67:112-119.

63. Mahjoub MR, Montpetit B, Zhao L, Finst RJ, Goh B, Kim AC, Quarmby LM: The FA2 gene of Chlamydomonas encodes a NIMA family kinase with roles in cell cycle progression and microtubule severing during deflagellation. J Cell Sci 2002, 115:1759-1768.

64. Lauwaet T, Smith AJ, Reiner DS, Romiin EP, Wong CCL, Davids BJ, Shah SA, Yates JR, Gillin FD: Mining the Giardia genome and proteome for conserved and unique basal body proteins. Int J Parasitol 2011.

65. Miranda-Saavedra D, Stark MJ, Packer JC, Vivares CP, Doerig C, Barton GJ: The complement of protein kinases of the microsporidium Encephalitozoon cuniculi in relation to those of Saccharomyces cerevisiae and Schizosaccharomyces pombe. BMC Genomics 2007, 8:309.

66. Kulakova L, Singer SM, Conrad J, Nash TE: Epigenetic mechanisms are involved in the control of Giardia lamblia antigenic variation. Mol Microbiol 2006, 61:1533-1542.

67. Nohynkova E, Tumova P, Kulda J: Cell division of Giardia intestinalis: flagellar developmental cycle involves transformation and exchange of flagella between mastigonts of a diplomonad cell. Eukaryotic cell 2006 5:753-761.

68. Dawson SC: An insider's guide to the microtubule cytoskeleton of Giardia. Cell Microbiol 2010, 12:588-598.

69. GiardiaDB. [http://Giardiadb.org/].

70. TrichDB. [http://trichdb.org].

71. TriTrypDB. [http://tritrypdb.org].

72. Sonnhammer EL, von Heijne G, Krogh A: A hidden Markov model for predicting transmembrane helices in protein sequences. Proc Int Conf Intell Syst Mol Biol 1998, 6:175-182.

73. Lupas A, Van Dyke M, Stock J: Predicting coiled coils from protein sequences. Science 1991, 252:1162-1164.

74. Larkin MA, Blackshields G, Brown NP, Chenna R, McGettigan PA, McWilliam H, Valentin F, Wallace IM, Wilm A, Lopez R, Thompson JD, Gibson TJ, Higgins DG: Clustal W and Clustal $\times$ version 2.0. Bioinformatics 2007, 23:2947-2948.

75. Eddy SR: A new generation of homology search tools based on probabilistic inference. Genome Informatics 2009, 23:205-211.

76. Waterhouse AM, Procter JB, Martin DM, Clamp M, Barton GJ: Jalview Version 2-a multiple sequence alignment editor and analysis workbench. Bioinformatics 2009, 25:1189-1191.

77. Diamond LS, Harlow DR, Cunnick CC: A new medium for the axenic cultivation of Entamoeba histolytica and other Entamoeba. Trans $R$ Soc Trop Med Hyg 1978, 72:431-432.

78. Keister DB: Axenic culture of Giardia lamblia in TYI-S-33 medium supplemented with bile. Trans R Soc Trop Med Hyg 1983, 77:487-488.

79. Ward HD, Lev BI, Kane AV, Keusch GT, Pereira ME: Identification and characterization of taglin, a mannose 6-phosphate binding, trypsinactivated lectin from Giardia lamblia. Biochemistry 1987, 26:8669-8675.

80. Weiland ME, Palm JE, Griffiths WJ, MCCaffery JM, Svard SG: Characterisation of alpha-1 giardin: an immunodominant Giardia lamblia annexin with glycosaminoglycan-binding activity. Int J Parasitol 2003, 33:1341-1351.

81. Touz MC, Lujan HD, Hayes SF, Nash TE: Sorting of encystation-specific cysteine protease to lysosome-like peripheral vacuoles in Giardia lamblia requires a conserved tyrosine-based motif. J Biol Chem 2003, 278:6420-6426.

82. Knodler LA, Svard SG, Silberman JD, Davids BJ, Gillin FD: Developmental gene regulation in Giardia lamblia: first evidence for an encystationspecific promoter and differential 5' mRNA processing. Mol Microbiol 1999, 34:327-340. doi:10.1186/gb-2011-12-7-r66

Cite this article as: Manning et al:: The minimal kinome of Giardia lamblia illuminates early kinase evolution and unique parasite biology. Genome Biology 2011 12:R66.

\section{Submit your next manuscript to BioMed Central and take full advantage of:}

- Convenient online submission

- Thorough peer review

- No space constraints or color figure charges

- Immediate publication on acceptance

- Inclusion in PubMed, CAS, Scopus and Google Scholar

- Research which is freely available for redistribution 